NASA TECHNICAL NOTE

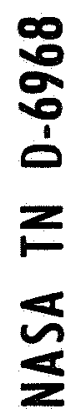

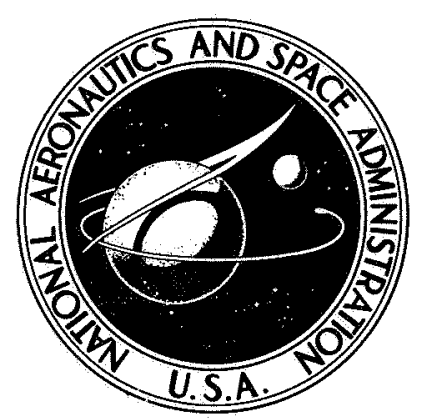

NASA TN D-6968

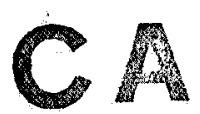

ivas

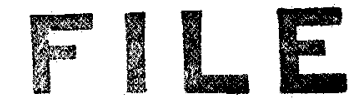

(1)

e

\title{
COMPARISON OF ADVANCED PROPULSION CONCEPTS FOR DEEP SPACE EXPLORATION
}

by W. E. Moeckel

Lewis Research Center

Cleveland, Ohio 44135

NATIONAL AERONAUTICS AND SPACE ADMINISTRATION - WASHINGTON, D. C. - SEPTEMBER 1972 


\title{
COMPARISON OF ADVANCED PROPULSION CONCEPTS FOR DEEP SPACE EXPLORATION
}

\author{
by W. E. Moeckel
}

Lewis Research Center

\section{SUMMARY}

Equations and charts are presented that permit rapid estimation of propulsionsystem performance requirements for some typical deep-space missions. The simplicity results from use of gravity-free equations of motion, which are shown to yield good approximations to trip times obtained with solar gravity and planetary motion included. The agreement is satisfactory for missions that do not enter or depart from low orbits about the major planets (Jupiter to Neptune). A number of advanced propulsion concepts for which performance estimates are available are compared with respect to their capability for flyby, rendezvous, and round-trip planetary missions. Based on these estimates, the gas-core nuclear fission rocket and the pulsed fusion rocket yield the fastest trip times to the near planets. For round trips to Jupiter and beyond, the controlled fusion rocket shows progressively superior capabilities. Because of the large uncertainties in current performance estimates, however, one can only conclude that all of these systems are competitive for solar system exploration. Several propulsion concepts based on use of impinging laser beams are noncompetitive with the other advanced concepts for deep-space missions. Requirements for the attainment of interstellar distances within a human lifetime are found to be some orders of magnitude beyond the capabilities of any propulsion concepts for which performance estimates are now possible.

\section{INTRODUCTION}

The relation between propulsion system performance and mission capability was discussed in reference 1 for current and future systems that seem suitable for manned exploration of the solar system. For the future systems the principles of operations and the performance to be expected were outlined. Since publication of that article, some changes have been made in estimated performance of gas-core nuclear fission rockets 
(ref. 2) and controlled thermonuclear fusion rockets (refs. 3 and 4). Studies have also been published on the performance possibilities of fusion microbomb propulsion systems (ref. 5) and laser-powered systems (refs. 6 to 8). One purpose of this report is therefore to update the discussion in reference 1. Another purpose is to extend the comparison in reference 1 to the use of advanced propulsion concepts for high-payload unmanned exploration of the planets, since such missions will probably precede manned flights. A third purpose is to illustrate the usefulness of simple field-free space trajectories for preliminary comparisons of advanced propulsion concepts.

\section{CLASSIFICATION OF PROPULSION SYSTEMS}

As in reference 1, the basis for comparison of propulsion systems is the trip time required for a given mission and payload ratio. The propulsion systems are again divided into the two types described in reference 1. Type I consists of those systems whose mission performance is primarily limited by the maximum specific impulse I attainable. For type II systems, mission performance is limited primarily by the mimimum specific mass $\alpha$ attainable ( $\alpha$ is the ratio of propulsion system mass to jet power produced).

The main reason for defining these two types of propulsion system is that they produce two different types of space trajectory because of their difference in thrust to weight ratio. In terms of specific impulse and specific mass, this ratio is

$$
\frac{F}{m_{p s} g_{o}}=\frac{2000}{\alpha^{\prime} \mathrm{Ig}_{o}^{2}}
$$

where $\alpha^{\prime}$ is specific mass in the usual units of kilograms per kilowatt and I is in seconds, $\mathrm{m}_{\mathrm{ps}}$ is propulsion system mass, and $\mathrm{g}_{\mathrm{o}}$ is gravitational acceleration at Earth's surface $\left(9.8 \mathrm{~m} / \mathrm{sec}^{2}\right)$. Equation (1) results from the following expression for jet power $P_{j}:$

$$
P_{j}=\frac{1}{2} \dot{m} v_{j}^{2}=\frac{F v_{j}}{2}=\frac{F g_{o}}{2} \text { watts }
$$

where $\dot{m}$ is propellant ejection rate and $v_{j}$ is jet exhaust velocity. (All symbols are defined in appendix A.)

Figure 1 shows the range of specific mass and specific impulse covered by the major type I and II systems. Also shown are lines of constant thrust to weight ratio from equation (1). This figure shows that the available studies of type I propulsion systems yield thrust to weight ratios generally above 0.05 . For the entire vehicle, these 


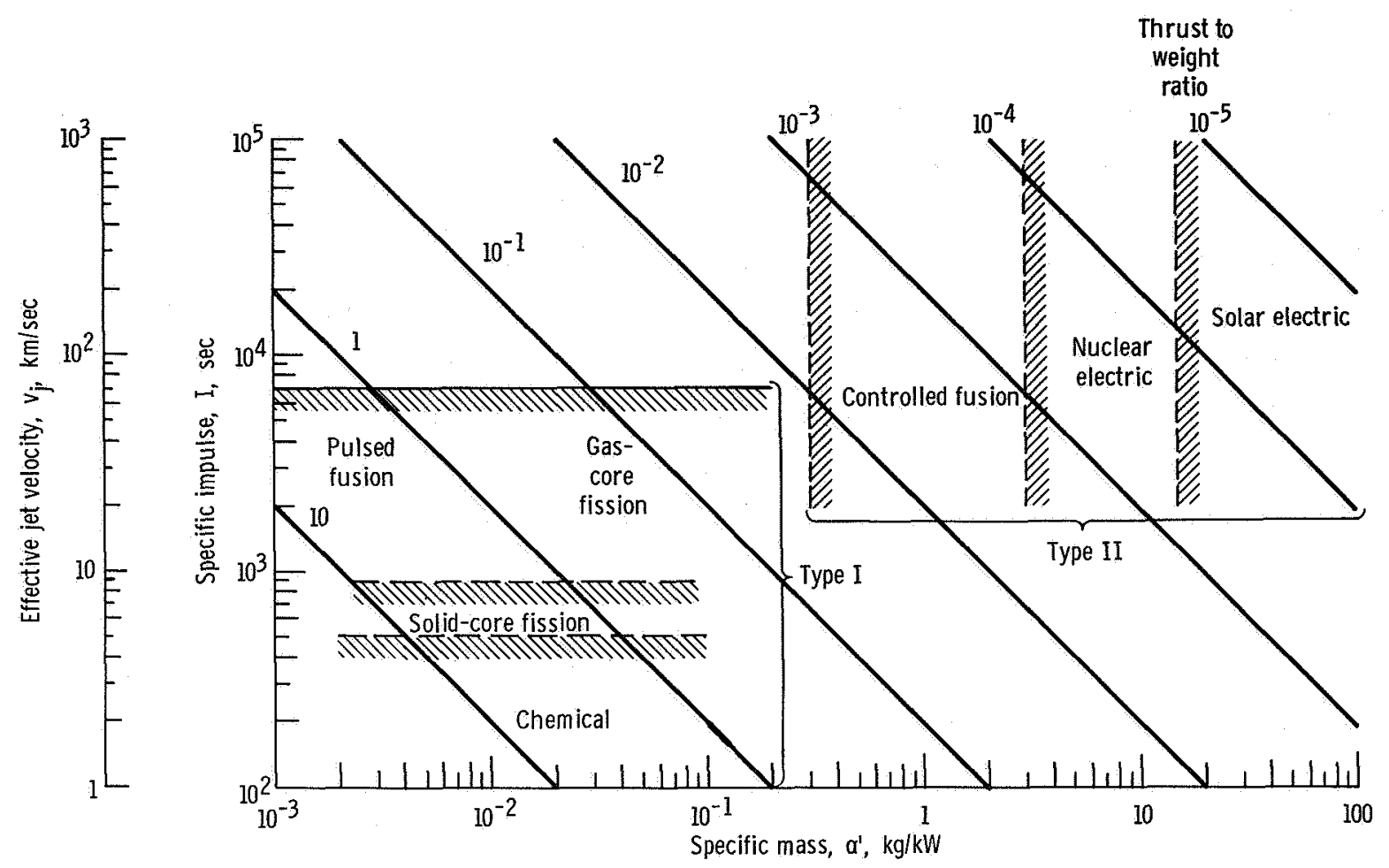

Figure 1. - Propulsion system performance parameters.

ratios could be much lower if propulsion system mass is only a small part of the total vehicle mass. However, the accelerations produced are generally sufficiently high that the propulsion time is very much smaller than the trip time for planetary missions, so that the thrust can be considered to take place in impulsive bursts. This permits use of unpowered (free fall) trajectory equations.

Type II systems, since they are not specific-impulse limited, can produce the optimum specific impulse needed to minimize the sum of propellant and propulsion system mass. However, as figure 1 shows, for high specific impulse they have thrust to weight ratios less than 0.01 . For such low accelerations, propulsion time may be of the same order of magnitude as trip time. In fact, for gravity-free space the optimum propulsion time for type II systems is readily shown to be two-thirds of the total trip time. The separation into types $I$ and $I I$ can be regarded as equivalent to the more conventional division into high-thrust and low-thrust propulsion systems.

The performance estimates shown in figure 1 differ from the values of reference 1 only for the most advanced concepts. For the controlled-fusion rocket, further optimization of system masses and consideration of higher power has reduced the estimated specific mass from 1 to about 0.3 kilogram per kilowatt (ref. 3 ).

For the gas-core fission rocket, more recent analysis using cooled chamber walls and radiative heat rejection (ref. 2) resulted in an increase in maximum specific impulse 
from about 2500 seconds to as high as 7000 seconds, with thrust to weight ratios as high as 0.17 .

The pulsed fusion system, propelled by a series of laser-ignited fusion-powered explosions, was not included in reference 1 , because no system mass and performance studies were available. Since then, reference 5 has appeared, with estimated maximum specific impulse of about 5000 to 7000 seconds. This (as yet uncertain) limit is imposed primarily by ablation of the "pusher" used to transform the shock impulses into a moderate acceleration of the vehicle and by ability to direct the blast within small angles. Thrust to weight ratios as high as 3.6 are estimated in reference 5 for this propulsion system. Its projected performance is therefore superior to that of the gas-core fission rocket. However, the feasibility studies of the pulsed fusion system are less advanced than those for the gas core fission rockets, and the performance estimates may have correspondingly greater uncertainty.

Other advanced propulsion concepts that have been proposed are not included in figure 1 either because they lack sufficient physical realism to estimate performance or because they can be considered as special cases of the systems shown. Thus, photon rockets are type II systems whose specific mass depends on the power source selected to generate the photons. Their specific impulse $\left(I \approx 3 \times 10^{7} \mathrm{sec}\right)$ is far beyond the optimum for any mission achievable with specific masses shown in figure 1. Although lower specific masses may eventually be possible by some as yet unknown method (such as direct mass annihilation) no basis for estimates is now available.

Other proposed forms of propulsion involve the use of powerful lasers stationed on the Earth, Moon, or an Earth satellite. These lasers would be directed at the vehicles to be propelled. The impinging laser power would be used in one of three ways: (1) to heat hydrogen propellant emerging from a rocket nozzle (ref. 6), (2) to generate onboard electric power for electric propulsion, or (3) to push the spacecraft directly by reflecting or absorbing the laser radiation (refs. 7 and 8 ).

Each of these methods shares the technological problems associated with generating very high power, highly collimated laser beams and transmitting them with high pointing accuracy over long distances. If the required huge power stations become available and if nearly diffraction-limited laser beam divergence is achievable in giant beams, transmission distances of several thousand kilometers may become feasible without excessive intensity drop using optical frequencies and very large optics. Even greater transmission distances could be visualized if far ultraviolet or X-ray lasers turn out to be feasible, but no plausible methods of generating highly collimated beams using such highenergy photons have as yet been proposed. Use of laser transmitting stations for propulsion is limited to an initial propulsion period on departure from the vicinity of the station. Space mission capability is therefore limited to flyby missions unless other forms of propulsion are carried along. 
Method (1) (a type I system) could theoretically produce specific impulses comparable with those of a gas core fission rocket, but without the nuclear problems. It could therefore conceivably be used to launch from the Earth's surface (ref. 6).

Method (2) would correspond to a type II system (electric propulsion) with specific mass dependent on the type of conversion system. If photovoltaic cell arrays are used, specific masses comparable with those of solar-electric propulsion systems should be achieved, with perhaps some (as yet unknown) advantage in conversion efficiency due to monochromaticity and higher intensity. However, no great increase in deep space mission capability seems likely from this concept.

Method (3) is similar to the "photon sails" frequently discussed for using solar radiation pressure in planetary space, but the laser could produce higher initial radiation pressure. Because the specific impulse is infinite (no on-board propellant is ejected), such systems are neither type I nor type II. Their mission performance is limited instead by the thrust to weight ratio attainable, which in turn is determined by the tolerable or attainable intensity of impinging radiation and the allowable thinness of the reflecting sail.

Performance parameters for methods (1) and (2) are thus included in the systems shown in figure 1 while method (3) requires a different type of analysis. Such an analysis is presented in appendix $B$ and leads to the conclusion that the method is not competitive with the systems in figure 1 for beam power levels that seem achievable in the foreseeable future.

\section{MISSIONS IN FIELD-FREE SPACE}

The simplest approach to estimating the mission capability of propulsion systems is to evaluate their performance in gravity-free space. The resulting relation between distance travelled and trip time shows primarily relative propulsion system effectiveness, but it also yields a good approximation to accurately computed planetary trip times for certain types of missions. The limitations of these field-free mission studies are considered in a later section.

Three types of mission are considered: flyby, rendezvous, and round trip. For each mission, the field-free equations approximate the energy requirements for that portion of the mission that excludes escape from the departure planet and capture by the destination body. Thus, for a flyby mission, only a single propulsion period is required, and the energy increment corresponds to that needed after achievement of escape velocity from the Earth. For the (one-way) rendezvous mission, two propulsion periods are needed, the first to achieve additional velocity beyond Earth escape for transfer to the destination, and the second to match the velocity of the destination planet or object. For the round-trip mission, four propulsion periods are needed: the first two for the outgoing 
rendezvous mission and the second two for the return rendezvous mission. In the fieldfree approximation, the vehicle begins and ends its rendezvous and round-trip mission legs at zero velocity. Consequently, each propulsion period provides the same velocity increment.

\section{Type I Propulsion System}

For type I propulsion systems, the velocity increments are produced impulsively and the three mission types are represented as follows:

Flyby -

$$
R=(\Delta v) T
$$

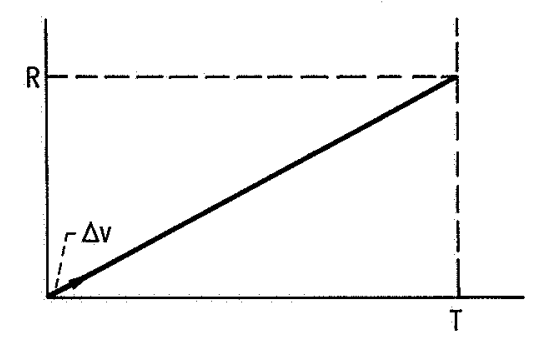

Rendezvous -

$$
R=\left(\frac{\Delta v}{2}\right) T
$$

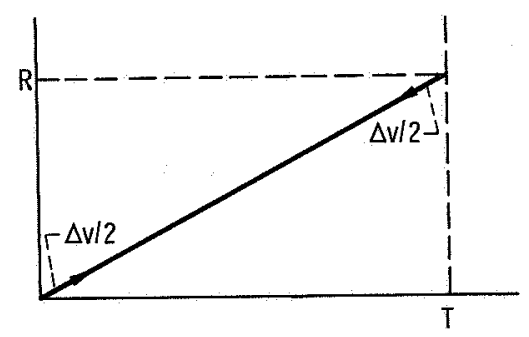


Round trip -

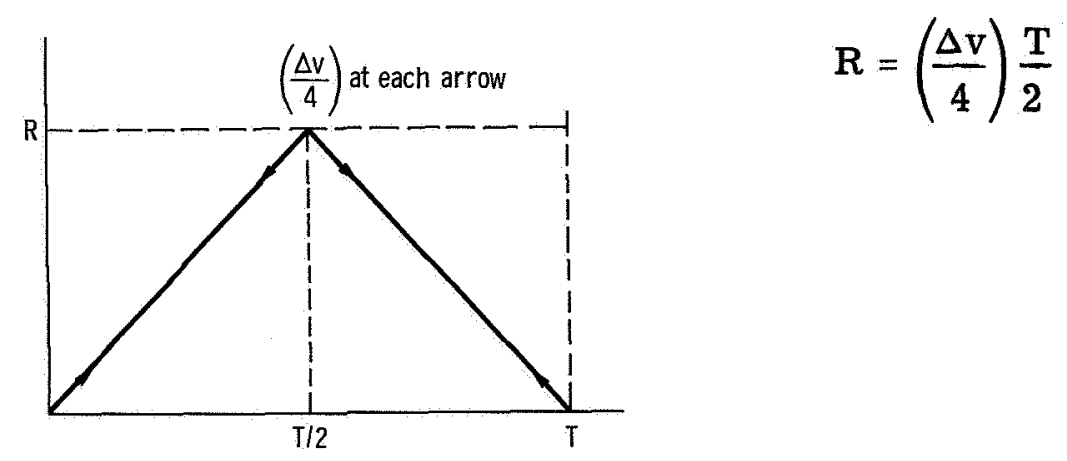

For each mission type $R$ is the distance to the destination, $T$ is the total trip time, and $\Delta \mathrm{v}$ is the total velocity increment needed for the mission. Thus, the rendezvous mission requires twice the $\Delta \mathrm{v}$ of the flyby mission, and the round-trip mission requires eight times the $\Delta v$ of the flyby mission for a given trip time.

To find $\Delta v$ achievable in terms of specific impulse (the primary type I performance parameter), consider a multistage vehicle, with all mass ratios identical for each stage. Then the total initial mass $m_{0}$ of the $(n+1)$ stage can be written

$$
m_{o, n+1}=m_{o, n}-m_{p r, n}-m_{t, n}-m_{p s, n}
$$

where $\mathrm{m}_{\mathrm{pr}}$ is propellant mass, $\mathrm{m}_{\mathrm{t}}$ is propellant tankage mass, and $\mathrm{m}_{\mathrm{ps}}$ is the mass of the propulsion system and any remaining vehicle structure. The tankage mass is generally considered to be proportional to propellant mass $\left(\mathrm{m}_{t}=\mathrm{km}_{\mathrm{pr}}\right)$ so that equation (6) can be written as

$$
\frac{\mathrm{m}_{\mathrm{o}, \mathrm{n}+1}}{\mathrm{~m}_{\mathrm{o}, \mathrm{n}}}=1-(1+\mathrm{k}) \frac{\mathrm{m}_{\mathrm{pr}, \mathrm{n}}}{\mathrm{m}_{\mathrm{o}, \mathrm{n}}}-\gamma
$$

where $\gamma=\mathrm{m}_{\mathrm{ps}, \mathrm{n}} / \mathrm{m}_{\mathrm{o}, \mathrm{n}}$. The propellant mass is given by the rocket equation:

$$
m_{p r, n}=m_{o, n}\left(1-e^{-\Delta v_{n} / v_{j}}\right)
$$

where $v_{j}$ is the effective exhaust velocity of the rocket. Hence, equation (7) becomes

$$
\frac{m_{o, n+1}}{m_{o, n}}=(1+k) e^{-\Delta v_{n} / v_{j}}-k-\gamma
$$

The net payload of the mission $\mathrm{m}_{\text {pay }}$ can be regarded as the initial mass of the $(\mathrm{N}+1)$ stage where $\mathrm{N}$ is the total number of propulsion stages. Thus, 


$$
\frac{m_{\text {pay }}}{m_{o, 1}}=\left[(1+k) e^{-\Delta v_{n} / v_{j}}-(k+\gamma)\right]^{N}
$$

From equation (8), the total $\Delta \mathrm{v}$ achievable is

$$
\Delta \mathrm{v} \equiv \mathrm{N} \Delta \mathrm{v}_{\mathrm{n}}=N g_{\mathrm{o}} \mathrm{I} \ln \left[\frac{1+\mathrm{k}}{\left(\frac{\mathrm{m}_{\mathrm{pay}}}{\mathrm{m}_{\mathrm{o} 1}}\right)^{1 / \mathrm{N}}+\mathrm{k}+\gamma}\right]
$$

where $v_{j}=g_{0} I$ has been substituted.

The best $\Delta \mathrm{v}$ achievable with a type I propulsion system (corresponding to negligible $\mathrm{k}$ and $\gamma$ relative to payload per stage) is

$$
\Delta v_{\max }=N g_{0} I \ln \left(\frac{m_{o 1}}{m_{\text {pay }}}\right)^{1 / N}
$$

Use of equation (9) in equations (3), (4), or (5) permits evaluation of distance achievable as functions of trip time for any nonrelativistic missions (i.e., those for which $\Delta v$ is much less than the speed of light).

\section{Type II Propulsion System}

For type II systems, the propulsion time is a major portion of total trip time, so that simple impulsive velocity increments cannot be assumed. The mass ratio per stage, as for type $I$, is given by equation (7). Since the propulsion system mass ratio $\gamma$ is generally much larger than $\mathrm{k}$ for these systems, $\mathrm{k}$ can be neglected. As shown in reference 1 and elsewhere, equation (7) can be written as

$$
\frac{m_{o, n+1}}{m_{o, n}}=\left(1+\frac{\alpha J_{n}}{2 \gamma}\right)^{-1}-\gamma
$$

and the propellant mass ratio is

$$
\frac{\mathrm{m}_{\mathrm{pr}, \mathrm{n}}}{\mathrm{m}_{\mathrm{o}, \mathrm{n}}}=1-\left(1+\frac{\alpha \mathrm{J}_{\mathrm{n}}}{2 \gamma}\right)^{-1}
$$


where $\alpha$ is the propulsion system specific mass $(\mathrm{kg} / \mathrm{W})$ and

$$
\mathrm{J}_{\mathrm{n}}=\int_{0}^{\mathrm{T}} \mathrm{pn} \mathrm{a}^{2} \mathrm{dt} \equiv \mathrm{a}_{\mathrm{o}}^{2} \mathrm{~T}_{\mathrm{pn}} \mathrm{m}^{2} / \mathrm{sec}^{3}
$$

The quantity $\mathrm{J}_{\mathrm{n}}$ is called the mission difficulty parameter (per stage), $a_{0}$ is the mean acceleration, and $\mathrm{T}_{\mathrm{pn}}$ is the propulsion time during each propulsion period. Optimization of the mass ratio in equation (11) then yields

$$
\gamma_{\mathrm{opt}}=\sqrt{\frac{\alpha \mathrm{J}_{\mathrm{n}}}{2}}\left(1-\sqrt{\frac{\alpha \mathrm{J}_{\mathrm{n}}}{2}}\right)
$$

Using this optimum value in equation (11) yields

$$
\frac{m_{0, n+1}}{m_{0, n}}=\left(1-\sqrt{\frac{\alpha J_{n}}{2}}\right)^{2}
$$

and the payload ratio with $\mathrm{N}$ stages becomes

$$
\frac{m_{\text {pay }}}{m_{01}}=\left(1-\sqrt{\frac{\alpha J_{n}}{2}}\right)^{2 \mathrm{~N}}
$$

The total mission difficulty parameter in terms of specific mass and payload ratio is then

$$
\alpha J \equiv N \alpha J_{n}=2 N\left[1-\left(\frac{m_{\text {pay }}}{m_{o 1}}\right)^{1 / 2 N}\right]^{2}
$$

In terms of total propulsion time $T_{p}$ equation (13) yields

$$
J \equiv N J_{n}=\mathrm{Na}_{\mathrm{o}}^{2} \mathrm{~T}_{\mathrm{pn}}=\mathrm{a}_{\mathrm{o}}^{2} \mathrm{~T}_{\mathrm{p}}
$$

The total velocity increment is

$$
\Delta v=a_{o} T_{p}=\sqrt{J T_{p}}=\sqrt{\frac{2 N T_{p}}{\alpha}}\left[1-\left(\frac{m_{p a y}}{m_{o 1}}\right)^{1 / 2 N}\right]
$$


Equations (17) to (19) enable evaluation of distance versus trip time relations in terms of the payload ratio and the primary performance parameter $\alpha$.

The distance versus time relation for the three types of mission are derived by simple addition of constant-acceleration and coasting periods:

Flyby -

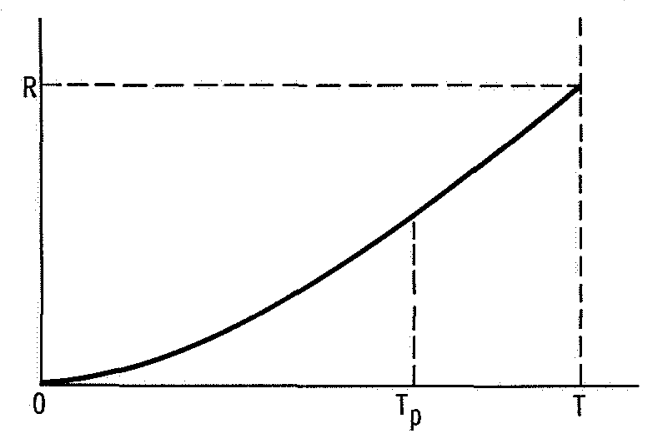

$$
\begin{aligned}
R & =\frac{1}{2} a_{o} T_{p}^{2}+a_{o} T_{p}\left(T-T_{p}\right) \\
& =\sqrt{\frac{J}{T_{p}}}\left(T T_{p}-\frac{1}{2} T_{p}^{2}\right)
\end{aligned}
$$

Differentiation yields $\left(T_{p}\right)_{\text {opt }}=(2 / 3) T$, so that, with equations (17) and (19)

$$
\begin{aligned}
\mathrm{R} & =\sqrt{\frac{2 \mathrm{~N}}{\alpha}}\left[1-\left(\frac{\mathrm{m}_{\mathrm{pay}}}{\mathrm{m}_{\mathrm{o} 1}}\right)^{1 / 2 \mathrm{~N}}\right]\left(\frac{2}{3} \mathrm{~T}\right)^{3 / 2} \\
& =\Delta \mathrm{v}\left(\frac{2}{3} \mathrm{~T}\right)
\end{aligned}
$$

Rendezvous -

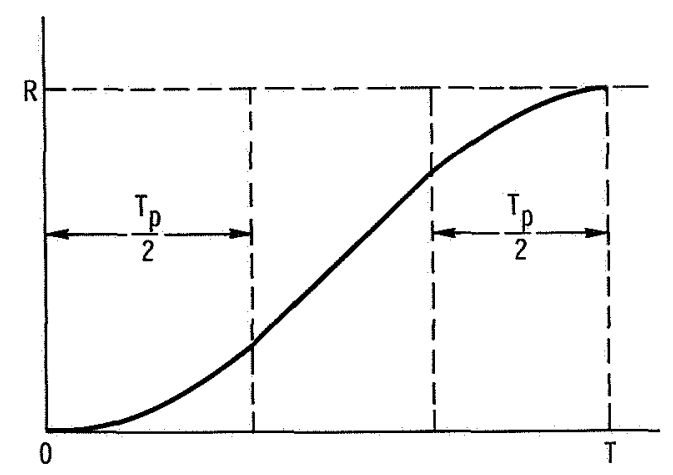

$$
\begin{aligned}
R & =2\left(\frac{a_{0}}{2}\right)\left(\frac{T_{p}}{2}\right)^{2}+\frac{a_{0} T_{p}}{2}\left(T-T_{p}\right) \\
& =\frac{1}{2} \sqrt{\frac{J}{T_{p}}}\left(T_{p} T-\frac{1}{2} T_{p}^{2}\right)
\end{aligned}
$$


Optimization again yields $\left(T_{p}\right)_{\text {opt }}=(2 / 3) T$, so that

$$
\begin{aligned}
\mathrm{R} & =\frac{1}{2} \sqrt{\frac{2 \mathrm{~N}}{\alpha}}\left[1-\left(\frac{\mathrm{m}_{\mathrm{pay}}}{\mathrm{m}_{\mathrm{o} 1}}\right)^{1 / 2 \mathrm{~N}}\right]\left(\frac{2}{3} \mathrm{~T}\right)^{3 / 2} \\
& =\frac{\Delta \mathrm{v}}{2}\left(\frac{2}{3} \mathrm{~T}\right)
\end{aligned}
$$

Round trip -

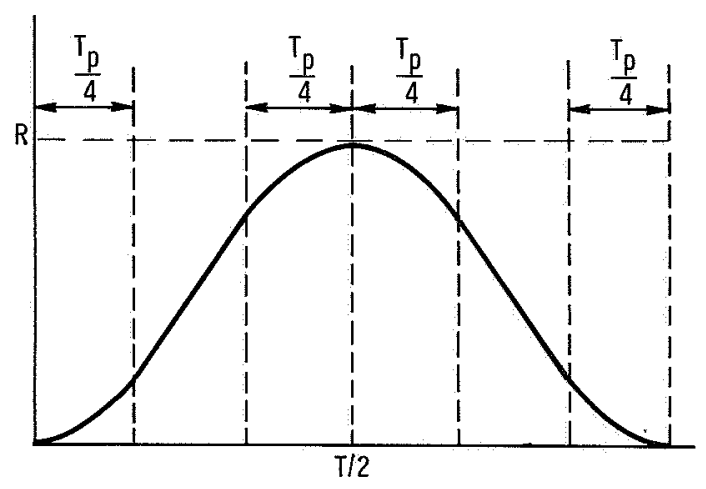

$$
\begin{aligned}
R & =2\left(\frac{a_{0}}{2}\right)\left(\frac{T_{p}}{4}\right)^{2}+\frac{a_{o} T_{p}}{4}\left(\frac{T}{2}-\frac{T_{p}}{2}\right) \\
& =\frac{1}{8} \sqrt{\frac{J}{T_{p}}}\left(T_{p} T-\frac{1}{2} T_{p}^{2}\right)
\end{aligned}
$$

Again, $\left(\mathrm{T}_{\mathrm{p}}\right)_{\text {opt }}=(2 / 3) \mathrm{T}$, so that

$$
\begin{aligned}
R & =\frac{1}{8} \sqrt{\frac{2 \mathrm{~N}}{\alpha}}\left[1-\left(\frac{\mathrm{m}_{\mathrm{pay}}}{\mathrm{m}_{\mathrm{o} 1}}\right)^{1 / 2 \mathrm{~N}}\right]\left(\frac{2}{3} \mathrm{~T}\right)^{3 / 2} \\
& =\frac{\Delta \mathrm{v}}{8}\left(\frac{2}{3} \mathrm{~T}\right)
\end{aligned}
$$

As for type I systems, the distances that can be travelled for a given trip time, payload ratio, and propulsion system parameter are in the ratio $1: \frac{1}{2}: \frac{1}{8}$ for flyby, rendezvous, and round trip, respectively. The range of validity of the above expressions is again limited to nonrelativistic velocities.

Another quantity of interest is the magnitude of the optimum specific impulse associated with these type II missions. From the expressions $\mathrm{F}=\dot{\mathrm{m}}_{\mathrm{j}}$ and $\mathrm{m}_{\mathrm{pr}, \mathrm{n}}=\dot{\mathrm{m} T} \mathrm{pn}$ and with the aid of equation (2),

$$
\frac{m_{p r, n}}{m_{o, n}}=\frac{F T_{p n}}{m_{o n} v_{j}}=\frac{2 P_{j}}{m_{p s, n}} \frac{m_{p s, n}}{m_{o, n}} \frac{T_{p n}}{v_{j}^{2}}=2 \frac{\gamma}{\alpha} \frac{T_{p n}}{v_{j}^{2}}
$$


Using equations (12), (14), and (16), equation (23) yields

$$
\mathrm{v}_{\mathrm{j}, \text { opt }}^{2} \equiv \mathrm{g}_{\mathrm{o}}^{2} \mathrm{I}_{\mathrm{opt}}^{2}=\frac{2 \mathrm{~T}_{\mathrm{pn}}}{\alpha}\left(\frac{\mathrm{m}_{\mathrm{pay}}}{\mathrm{m}_{\mathrm{o} 1}}\right)^{1 / 2 \mathrm{~N}}=\frac{4}{3} \frac{\mathrm{T}}{\alpha \mathrm{N}}\left(\frac{\mathrm{m}_{\mathrm{pay}}}{\mathrm{m}_{\mathrm{o} 1}}\right)^{1 / 2 \mathrm{~N}}
$$

or

$$
\mathrm{I}_{\mathrm{opt}}=\left(\frac{4 \mathrm{~T}}{3 \mathrm{~g}_{\mathrm{o}}^{2} \mathrm{~N} \alpha}\right)^{1 / 2}\left(\frac{\mathrm{m}_{\mathrm{pay}}}{\mathrm{m}_{\mathrm{o} 1}}\right)^{1 / 4 \mathrm{~N}}
$$

In terms of velocity increment (eq. (19)), the optimum exhaust velocity is

$$
v_{j, o p t}=\frac{\Delta v}{N} \frac{\left(\frac{m_{\text {pay }}}{m_{o 1}}\right)^{1 / 4 N}}{1-\left(\frac{m_{\text {pay }}}{m_{01}}\right)^{1 / 2 N}}
$$

Thus, the optimum exhaust velocity is comparable with the required velocity increment per stage.

\section{Summary of Equations}

The preceding derivations have been carried out in the international system of units. For astronomical distances and long trip times, it is convenient to express $R$ in astronomical units $\left(1 \mathrm{AU}=1.495 \times 10^{11} \mathrm{~m}\right)$ and $\mathrm{T}$ in years $\left(1 \mathrm{yr}=3.155 \times 10^{7} \mathrm{sec}\right)$. Furthermore, the specific mass is generally expressed in kilograms per kilowatt (denoted by $\alpha^{*}$ ) rather than kilograms per watt, $\alpha$. In these units, the equations for distance versus trip time are as follows:

Type I propulsion, flyby mission -

$$
\mathrm{R}_{\mathrm{F}}=4.8 \times 10^{-3} \text { NIT } \log _{10}\left[\frac{1+\mathrm{k}}{\left(\frac{\mathrm{m}_{\text {pay }}}{\mathrm{m}_{\mathrm{o} 1}}\right)^{1 / \mathrm{N}}+\mathrm{k}+\gamma}\right]
$$


Type II propulsion, flyby mission -

$$
R_{F}=29 \sqrt{\frac{N}{\alpha^{\prime}}} T^{3 / 2}\left[1-\left(\frac{m_{\text {pay }}}{m_{o 1}}\right)^{1 / 2 N}\right]
$$

For both type I and type II propulsion, distances for rendezvous and round-trip missions are related to the flyby distance by

$$
\mathrm{R}_{\mathrm{R}}=\frac{1}{2} \mathrm{R}_{\mathrm{F}}
$$

and

$$
\mathrm{R}_{\mathrm{RT}}=\frac{1}{8} \mathrm{R}_{\mathrm{F}}
$$

For the following comparisons of relative mission performance, the mass ratio per stage $m_{0, n+1} / m_{0, n}$ is assumed to be equal to 0.1 . Consequently, in equations (25) and (26), $\left(\mathrm{m}_{\mathrm{pay}} / \mathrm{m}_{\mathrm{o}}\right)^{1 / \mathrm{N}}=0.1$. Also for type I systems, $\mathrm{k}$ and $\gamma$ are assumed to be zero to illustrate best possible performance. Equations (25) and (26) then become

$$
\mathrm{R}_{\mathrm{F}}=4.8 \times 10^{-3} \mathrm{NIT}
$$

for type I and

$$
R_{F}=19.8 \sqrt{\frac{N}{\alpha^{\prime}}} T^{3 / 2}
$$

for type II.

The expression for optimum type II specific impulse becomes for these mass ratios and units (from eq. (24)):

$$
I_{\text {opt }}=1.18 \times 10^{4} \sqrt{\frac{\mathrm{T}}{\mathrm{N} \alpha^{\prime}}}
$$

For most values of $\mathrm{T}$ and $\mathrm{N} \alpha^{\prime}$ of interest for advanced propulsion missions, this value is greater than the maximum estimated value of 7000 seconds for the type I systems in figure 1. Consequently, the distinction between types I and II remains a useful one at these performance levels. 


\section{MISSION CAPABILITY}

\section{Interstellar Distances}

Results from equations (25a) and (26a) are shown in figures 2(a) and (b), respectively, for values of distances, trip times, and performance parameters to the limits of validity of nonrelativistic equations. The plots are for four-stage vehicles with an overall payload ratio of $10^{-4}(0.1$ per stage).

Figure 2 shows that flyby or rendezvous missions to the nearest star (4 light years) in trip times less than 20 years will require specific impulses of the order of $10^{6}$ seconds for type I systems, or specific masses of the order of $10^{-4}$ kilogram per kilowatt for type II systems. These parameters are obviously beyond those attainable with any known propulsion concept. The required optimum specific impulse for type II systems (eq. $(24 b))$ is greater than $2 \times 10^{6}$ seconds. The corresponding exhaust velocity is about onetenth the speed of light.

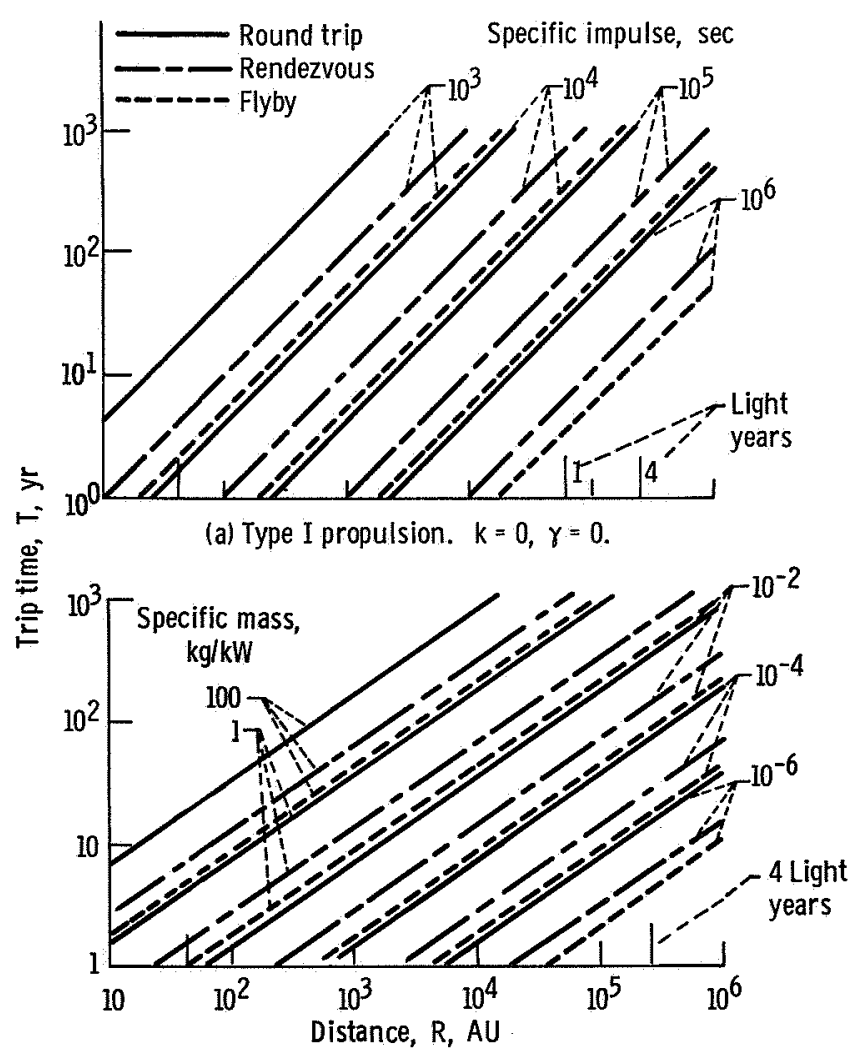

(b) Type II propulsion.

Figure 2. - Interstellar distance versus trip time in field-free space. Number of stages, 4. 


\section{Interplanetary Distances}

Results from equations (25a) and (26a) for interplanetary distances are shown in figure 3. The figure shows that for single-stage, round-trip missions to the outer planets (Neptune, Pluto) in trip times less than 5 years, a specific impulse greater than 10000 seconds is needed with type I systems, and a specific mass less than $1 \mathrm{kilog}$ ram per kilowatt is needed for type II systems. Figure 1 shows no type I system with this capability, but a type II system may be able to do it. Flyby missions to Pluto in less than 5 years require a specific impulse of about 1600 seconds with type I, and a specific mass of about 30 kilograms per kilowatt for type II systems. As figure 1 shows these performance values should be achievable with future systems of both types.

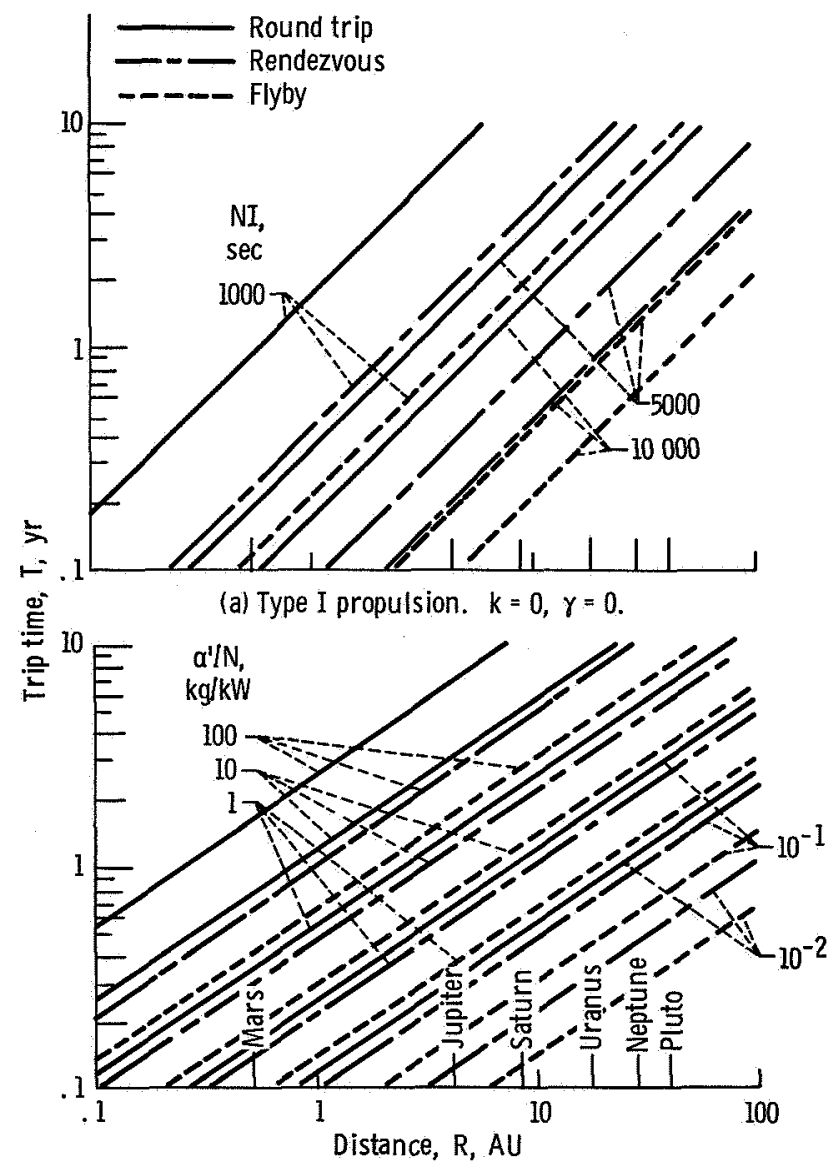

(b) Type II propulsion.

Figure 3. - Interplanetary distance versus trip time. Fieldfree space. 


\section{Comparison of Advanced Propulsion Systems}

Figure 4 compares trip-time requirements for advanced type I and type II systems that have performance parameters in the orders of magnitude shown in figure 1. Roundtrip missions are compared in figure 4(a) and one-way rendezvous missions in figure 4(b). For the round-trip mission a type II system with the lowest specific mass shown in figure $1(0.3 \mathrm{~kg} / \mathrm{kW})$ would produce lower trip time than a type I system with the highest specific impulse ( $I=7000 \mathrm{sec}$ ) for all planets beyond Jupiter. For the Jupiter trip, these systems yield about the same capability, while for the Mars trip the type I system provides faster trip times. These capabilities agree qualitatively with those of reference 9, which contains comparisons of several nuclear fission rockets and a nuclear fusion rocket for several specific missions. For the farthest planets even a relatively heavy type II system $\left(\alpha^{\prime} \approx 10 \mathrm{~kg} / \mathrm{kW}\right)$ is competitive with the most advanced type I systems of figure $1(I \approx 7000 \mathrm{sec})$. For the rendezvous mission (fig. $4(\mathrm{~b}))$, the cross-over point (where the best type II system of fig. 1 is faster than the best type I system) lies at a distance beyond Saturn.

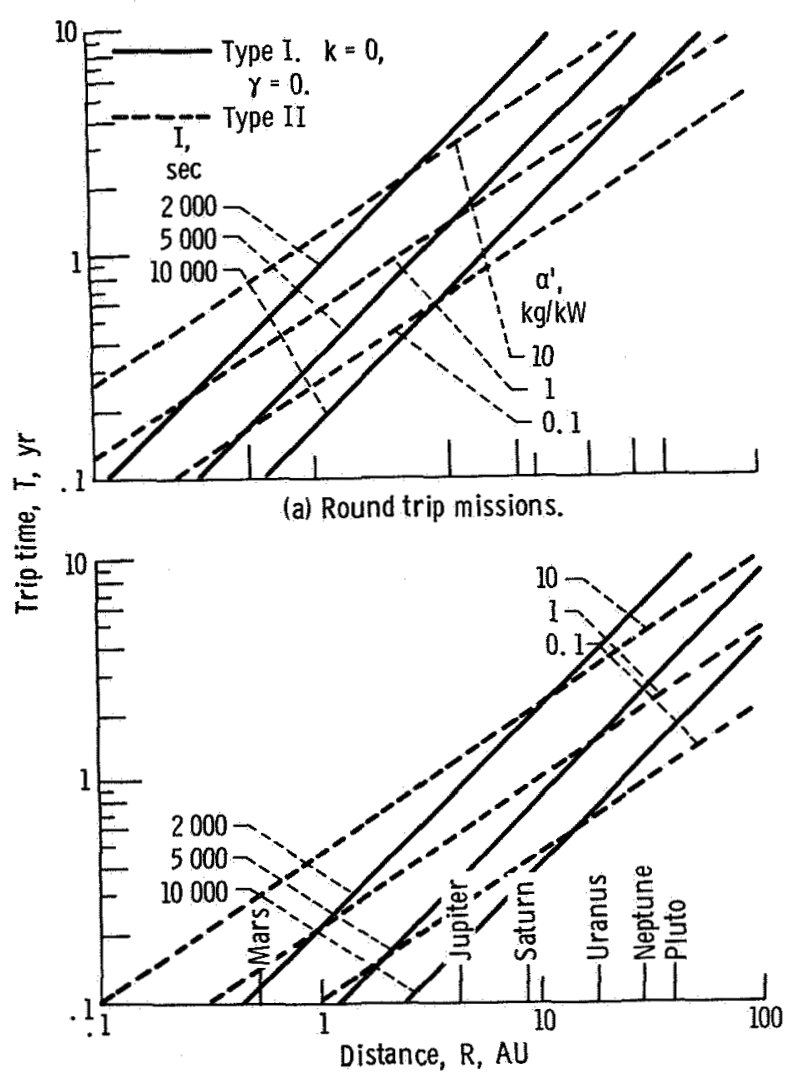

(b) Rendezvous (one-way) missions.

Figure 4. - Comparison of type I and type II propulsion for planetary distances. $N=1$. 
Because the feasibility of these advanced systems remains to be demonstrated, one cannot tell which of the performance estimates shown in figure 1 is most likely to survive without major deterioration, or whether some unforeseen problem will arise that eliminates a system from the competition. It is obviously much too soon to try to decide which of the major advanced propulsion concepts represented in figure 1 will turn out to be most useful. One can only conclude that they are competitive for planetary missions.

\section{VALIDITY OF GRAVITY-FREE APPROXIMATION}

One might expect that gravity-free mission calculations would agree closely with those calculated with gravity fields included when the kinetic energy needed for the mission becomes much greater than the maximum gravitational potential energy involved. This potential energy (per unit mass) in any gravity field is equal to $-G M / r=-v_{c}^{2}$ where $v_{c}$ is the circular orbital velocity at radius $r$ from the center of the gravitational mass M. The condition for validity of the field-free approximation should therefore be

$$
\frac{\Delta \mathrm{v}}{\mathrm{v}_{\mathrm{c}}}>>1
$$

where $v_{c}$ is the maximum circular velocity appropriate to the mission. The values of $\Delta v$ to be compared with $v_{c}$ are given by equations (9) and (19) for type I and type II systems, respectively. For $\mathrm{k}=\gamma=0$ and $\mathrm{m}_{\mathrm{o}, \mathrm{n}+1} / \mathrm{m}_{\mathrm{o}, \mathrm{n}}=0.1$, these equations become Type I:

$$
\Delta \mathrm{v}=22.6 \mathrm{NI} \mathrm{m} / \mathrm{sec}
$$

and type II:

$$
\Delta \mathrm{v}=1.4 \times 10^{5} \sqrt{\frac{\mathrm{NT}_{\mathrm{yr}}}{\alpha^{\prime}}} \mathrm{m} / \mathrm{sec}
$$

If $\left(\Delta v / v_{c}\right)>10$ is used as the criterion for negligibility of gravity fields, then these equations yield

$$
\mathrm{NI} \gtrsim 0.44 \mathrm{v}_{\mathrm{c}}
$$

and

$$
\frac{\alpha^{\prime}}{\mathrm{N}} \lesssim\left(\frac{14 \times 10^{3}}{\mathrm{v}_{\mathrm{c}}}\right)^{2} \mathrm{~T}_{\mathrm{yr}}
$$


where $\mathrm{v}_{\mathrm{c}}$ is in meters per second.

Alternatively, if $\Delta \mathrm{v}$ is expressed in terms of the field-free mission distance and time (eqs. (3) to (5) and (20) to (22)) these conditions become

Flyby:

$$
\frac{\mathrm{R}}{\mathrm{T}} \geq 10 \mathrm{fv} \mathrm{c}_{\mathrm{c}}
$$

Rendezvous:

Round trip:

$$
\frac{\mathrm{R}}{\mathrm{T}} \gtrsim 1.25 \mathrm{fv}_{\mathrm{c}}
$$

where $f=1.0$ for type I systems and $f=2 / 3$ for type II systems. Some pertinent values of $v_{c}$ are shown in table I.

As might be expected, the conditions for negligibility of solar and planetary gravity fields are amply satisfied for the range of parameters required for interstellar distances (fig. 2). However, for missions within the solar system and for the propulsion concepts shown in figure 1, these conditions are not necessarily satisfied. For example, for a type I propulsion system with $N I \approx 5000$, condition $(31)$ requires that $\mathrm{v}_{\mathrm{c}} \lesssim 10$ kilometers per second. For a type II system with $\alpha^{\prime} / \mathrm{N}=1$ kilogram per kilowatt, condition (32) requires $\mathrm{v}_{\mathrm{c}} \lesssim 14 \sqrt{\mathrm{T}_{\mathrm{yr}}}$ kilometers per second. Table $\mathrm{I}$ therefore indicates that one

TABLE I. - TYPICAL CIRCULAR VELOCITIES

IN SOLAR SYSTEM

\begin{tabular}{|l|c|c|c|c|}
\hline \multirow{2}{*}{ Planet } & \multicolumn{2}{|c|}{$\begin{array}{c}\text { Circular velocity at } \\
1.1 \text { times planet's radius }\end{array}$} & \multicolumn{2}{c|}{$\begin{array}{c}\text { Orbital velocity around } \\
\text { Sun at planet's distance }\end{array}$} \\
\cline { 2 - 5 } & $\mathrm{km} / \mathrm{sec}$ & $\mathrm{AU} / \mathrm{yr}$ & $\mathrm{km} / \mathrm{sec}$ & AU/yr \\
\hline Earth & 7.5 & 1.6 & 29.8 & 6.3 \\
Mars & 3.5 & .74 & 24.1 & 5.1 \\
Jupiter & 41.2 & 8.7 & 13.1 & 2.8 \\
Saturn & 25.5 & 5.4 & 9.7 & 2.0 \\
Uranus & 15.6 & 3.3 & 6.8 & 1.4 \\
Neptune & 14.0 & 3.0 & 5.4 & 1.1 \\
Pluto & 7.4 & 1.6 & 4.7 & 1.0 \\
\hline
\end{tabular}


might expect substantial errors in gravity-free calculations for missions that require departure from or capture into low orbits about the major planets (Jupiter to Neptune) and perhaps for any missions within the orbit of Jupiter. To estimate the magnitude of these errors, the gravity-free calculations must be compared with more accurate results.

\section{Effect of Solar Gravity Field}

The gravity-free mission times are compared in figure 5 with results from reference 1, wherein the effect of solar gravity was included for out-and-back trips with no stopover and no descent into planetary gravitational fields. For the solar-field results $R$ is the radial distance of travel. The actual distance along the conic-section path is, of course, considerably greater. For these missions, the pertinent $v_{c}$ is the Earth's orbital velocity, 29.8 kilometers per second. For the type I systems (fig. 5(a)) a value $\mathrm{k}=0.05$ was used (as in ref. 1). As expected from equation (31) the differences are largest at the lower specific impulse and essentially disappear for the highest values.

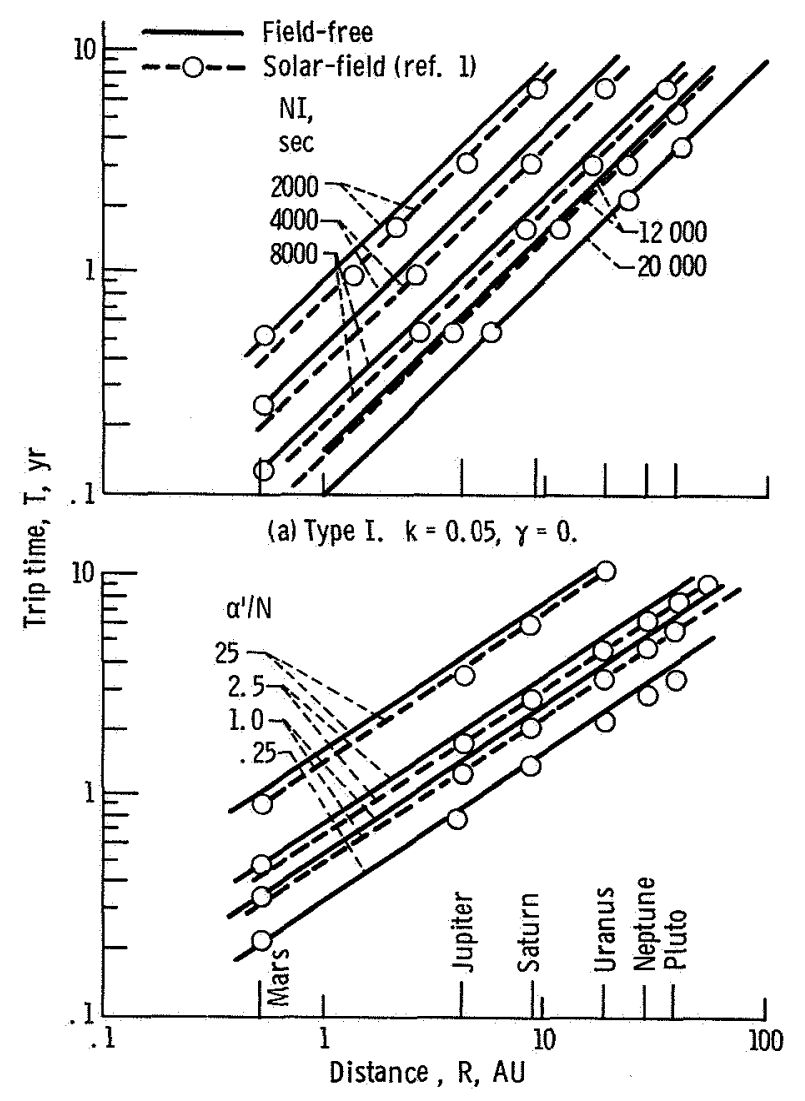

(b) Type II.

Figure 5. - Comparison of field-free and solar-field results. Round-trip missions. 
Even at $\mathrm{NI}=2000$ seconds $\left(\Delta \mathrm{v} / \mathrm{v}_{\mathrm{c}} \approx 1.5\right)$ the difference in trip time for a given distance is less than 30 percent.

For type II systems (fig. 5(b)), a similar trend toward agreement seems evident as $\alpha^{\prime} / \mathrm{N}$ decreases although there is some scatter in the values from reference 1.

In general, figure 5 shows that the use of field-free calculations yields good approximations for out-and-back trips to the planets as function of propulsion system performance parameters. Furthermore, the difference between field-free and solar-field results is in the same direction and about the same magnitude for type I and type II systems, so that relative trip times should be predicted even more accurately than absolute trip time by the field-free method.

The trips shown in figure 5 do not include stopover time at the destination or the effects of planetary motion. Stopover times can be added directly to the out-and-back trip times for both field-free and solar field calculations, but the neglect of planetary motion raises the question of whether the postulated missions are really possible. This neglect is likely to be most serious for trips to the near planets, where the more rapid angular motion of the destination planet may make use of minimum-energy trajectories (for a given total trip time) difficult or impossible. These questions were answered in reference 1 for the Earth-Mars round trip by referring to results from other references wherein planetary motions were included. These and other comparisons are shown explicitly in figure 6(a) for type I systems and 6(b) for type II systems. For the type I system, the trip times neglecting planetary motion (both with and without solar gravity) are very close to the more exact results, particularly for fast trip times. The data points from references 10 and 11 include departure and arrival at close Earth and Mars orbits, indicating that such low-orbit couplings are adequately represented by the field-free approximation for this mission. For type II systems comparison with values from reference 12 (fig. 6(b)) shows that the trip time is increased significantly when planetary motion is considered, particularly for the longer trip times and higher specific mass. The range of increase is from about 10 percent at $\alpha^{\prime} / \mathrm{N}=0.3$ to 25 percent at $\alpha^{\prime} / \mathrm{N}=3.0$ kilograms per kilowatt. These errors seem reasonable for preliminary evaluation of propulsion concepts, particularly since the system performance estimates are likely to be questionable by much larger margins.

Also shown for this mission is the effect of escape from and descent to low Earth orbits. These maneuvers increase trip times only slightly for $\alpha^{\prime}=0.3$ kilogram per kilowatt but have a large effect at higher specific mass. 


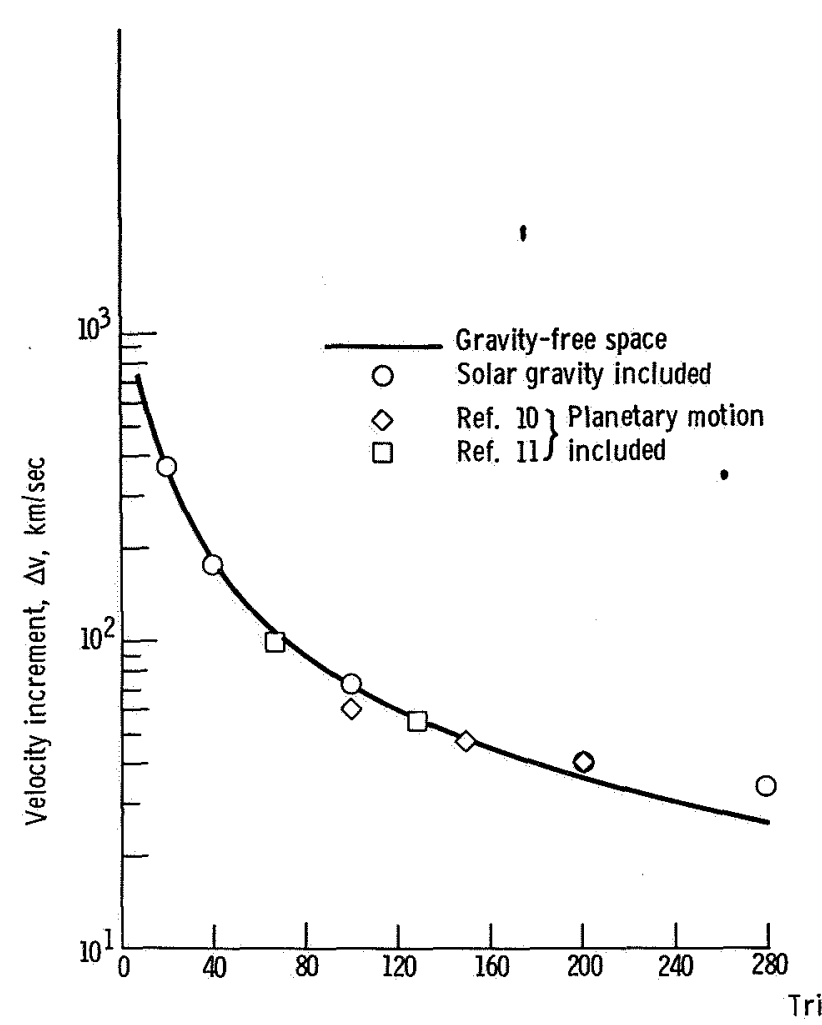

(a) Type I propulsion systems. $k=0.05, \gamma=0$.

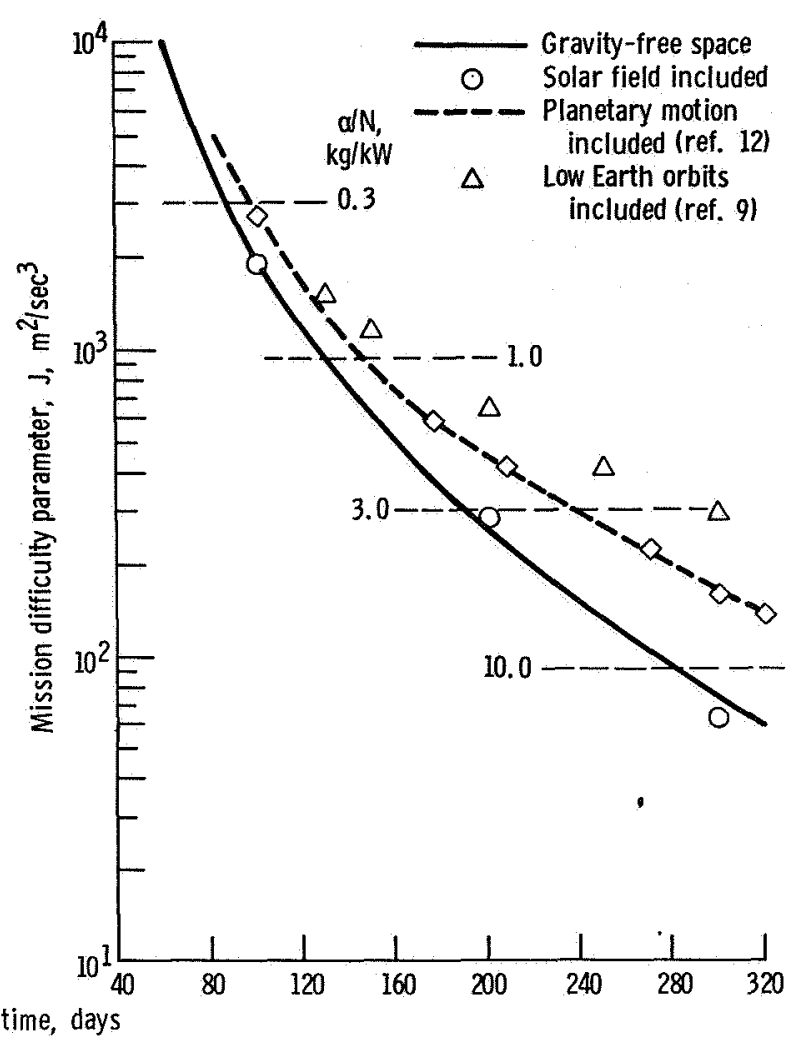

(b) Type II propulsion systems.

Figure 6. - Comparison of propulsion requirements for Mars round trip.

\section{Effect of Planetary Gravitational Fields}

If strong coupling into planetary orbits is required, the previous comparisons between type I and type II systems, as well as the trip time values themselves, may be considerably altered (as illustrated in fig. 6(b)).

Because of their lower thrust accelerations, type II systems require a longer time than type I systems to escape from or descend into such orbits. Furthermore, for type I systems the $\Delta \mathrm{v}$ values for escape and descent are not additive to the $\Delta v$ for interplanetary transfer. Rather the velocity increment $\Delta v_{\text {orb }}$ needed at departure from, or arrival at, a circular orbit is given by (ref. 13):

$$
\Delta v_{o r b}=\sqrt{v_{\infty}^{2}+2 v_{c o}^{2}}-v_{c o}
$$

where $\mathrm{v}_{\text {co }}$ is the orbital velocity at the departure or arrival orbit around the planet and $\mathrm{v}_{\infty}$ is the,departure or arrival velocity relative to the planet. This velocity $\mathrm{v}_{\infty}$ is known as the hyperbolic excess velocity, and corresponds to the $\Delta v$ used for each impulse in the gravity-free approximation. Equation (34) shows that $(\Delta v)_{\text {orb }}$ is less than 
$v_{\infty}$ for all $v_{\infty} \leq v_{c o} / 2$, so that the propulsion requirement to achieve a given velocity relative to a planet is generally reduced if the vehicle starts from a low planetary orbit. The ratio $(\Delta v)_{\text {orb }} / v_{\infty}$ reaches a minimum of $1 / \sqrt{2}$ when $v_{c o} / v_{\infty}=1 / \sqrt{2}$. Thus, the type I system acquires advantage over type II system in both time and reduced velocity increment if low planetary orbits are required.

For type II systems, two conditions are needed to establish negligibility of the planetary field: The escape time must be small relative to the trip time, and the $J$ needed for escape must be small relative to the $J$ for the interplanetary transfer. As might be expected, these two conditions are satisfied or violated simultaneously.

The time $T_{\text {esc }}$ required to achieve escape velocity from a circular planetary orbit having an orbital velocity $v_{c o}$ is shown in figure 12 of reference 14 to be

$$
\frac{\mathrm{a}_{\mathrm{o}} \mathrm{T}_{\text {esc }}}{\mathrm{v}_{\text {co }}} \leq 1
$$

This ratio is close to 1.0 for very low accelerations and approaches $\sqrt{2}-1$ for high accelerations and high exhaust velocity $v_{j}$. Figure 13 of reference 14 shows that condition (35) also applies for descent from zero relative velocity to an orbit with circular velocity $\mathrm{v}_{c o}$, provided that $\mathrm{v}_{\mathrm{j}} \gtrless 5 \mathrm{v}_{\mathrm{co}}$, which is easily satisfied by type II systems. Consequently, the maximum escape or descent time can be taken as $T_{\text {esc }}=v_{\text {co }} / a_{0}$. Since $a_{o}=\Delta v / T_{p}$ (eq. (19)) and $J=a_{o}^{2} T_{p}$ (eq. (18)), the relations between escape (or descent) parameters and interplanetary parameter become

$$
\frac{\mathrm{T}_{\text {esc }}}{\mathrm{T}_{\mathrm{p}}}=\frac{\mathrm{v}_{\text {co }}}{\Delta \mathrm{v}}=\frac{\mathrm{J}_{\text {esc }}}{\mathrm{J}}
$$

Thus, as before, the condition for negligibility of the planetary escape or descent phases is $\Delta \mathrm{v} \gg \mathrm{v}_{\mathrm{co}}$.

Consequently, as for type I systems, escape and descent to low planetary orbits about the minor planets should have small effect on the field-free mission estimates for advanced type II systems. But such maneuvers about the major planets would be expected to have large effects. As an example, for $\alpha^{\prime}=1 \mathrm{kilogram}$ per kilowatt, $\mathrm{T}_{\mathrm{yr}} \approx$ 0.5 , and $N=1$, equation (32) and table I show that the lowest allowable Jupiter orbit would be about 16 Jupiter radii for field-free estimates to be reasonably accurate.

A simple way to allow for descent and escape from planetary orbits with type II systems if such corrections are desired, is to add the value $\mathrm{J}_{\mathrm{esc}}=\mathrm{a}_{\mathrm{o}} \mathrm{T}_{\text {esc }}$ to the total $\mathrm{J}$ obtained from the field-free mission and to add $\mathrm{T}_{\text {esc }}$ to the field-free mission time, with $T_{\text {esc }}=v_{c o} / a_{0}$. The values of $a_{0}$, obtained from equations (20) to (22) with $\mathrm{T}_{\mathrm{p}}=2 / 3 \mathrm{~T}$, are as follows: 
Flyby -

$$
a_{0}=\frac{9}{4} \frac{R}{T^{2}} \mathrm{~m} / \mathrm{sec}^{2}
$$

Rendezvous -

Round trip -

$$
\left.a_{0}=18 \frac{R}{T^{2}}\right)
$$

To estimate the maximum effect of escape and descent to low orbit about a major planet, consider a rendezvous mission to Jupiter, starting from low Earth orbit and descending to 1.1 Jupiter radii. Figure 7(a) shows the magnitude of the reduction in trip time relative to field-free values for the type I systems. Figure 7(b) shows the corresponding increase in trip time for type II systems. The low-orbit values $(\Delta v)_{\text {orb }}$ for

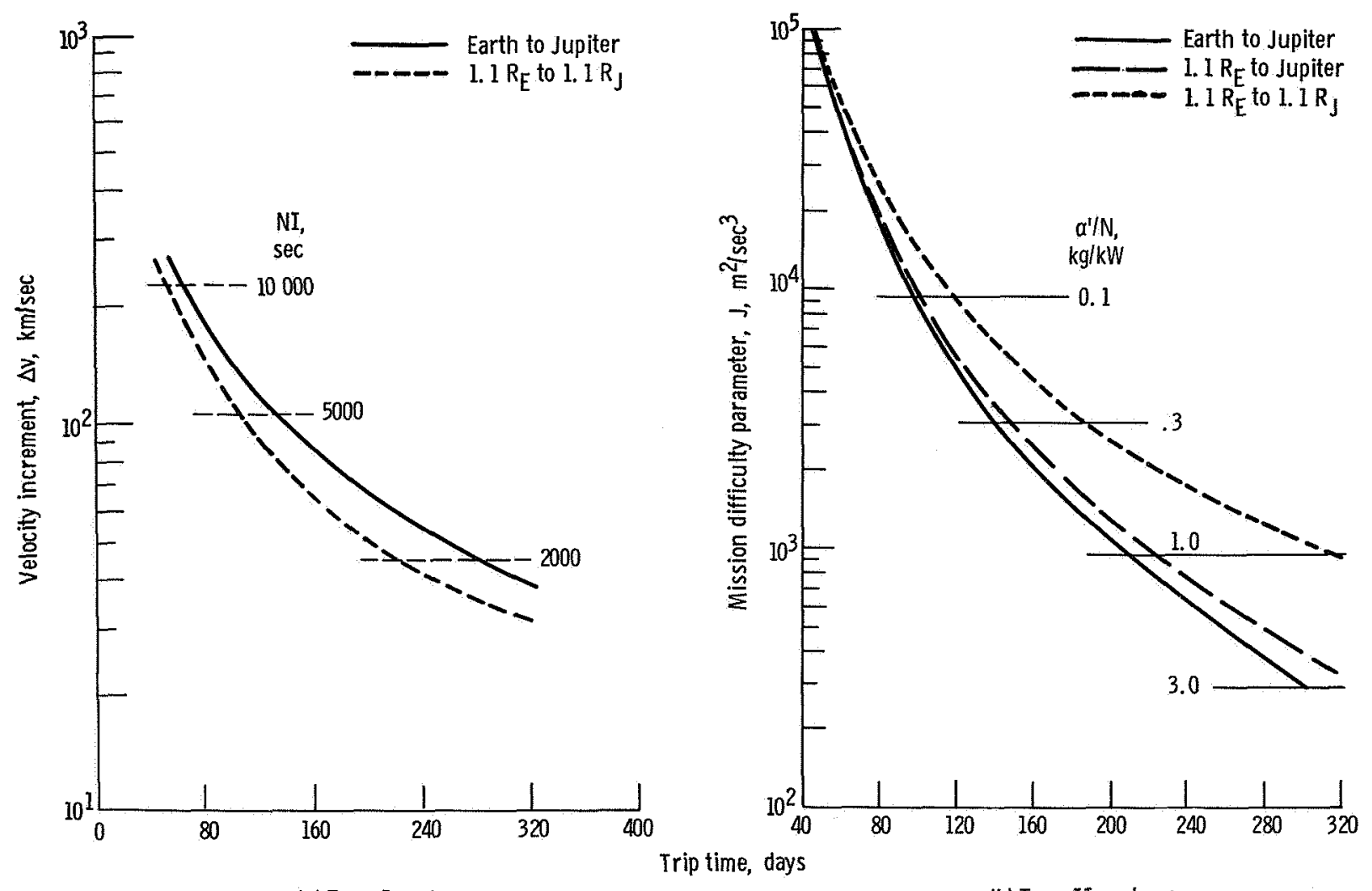

(a) Type-I systems.

(b) Type-II systems.

Figure 7. - Effect of entering and leaving low planetary orbits on trip time for Earth-Jupiter rendezvous mission. 
figure $7(a)$ were calculated from equation (34), using the same hyperbolic excess velocities as in reference 1 for $v_{\infty}$. The field-free values of $\Delta v$ from equations (3) to (5) could also be used for $v_{\infty}$ with little difference in results. For the type II system equation (35) was used to calculate escape and descent time, with $a_{0}$ determined from equation (37). The type I results show about a 20 -percent reduction in trip time, whereas the type II results show a range of increase in trip time from 20 percent at $\alpha^{\prime}=0.1$ kilogram per kilowatt to about 50 percent at $\alpha^{t} \approx 1$ kilogram per kilowatt.

The relatively large penalty for low-acceleration systems due to entering or leaving low orbits of major planets can be reduced somewhat (about 20 percent) by reoptimizing the acceleration or by using a higher acceleration for the descent and escape maneuvers. More substantial improvement could result by using an advanced type I system for the planetáry escape and capture maneuvers and a type II system for interplanetary propulsion. As for previous combinations of the two types (nuclear or chemical rockets with electric rockets, ref. 15) such a hybrid combination may show better performance than either type alone.

\section{Effect of Variations in $k, \gamma$, and Payload Ratio}

For type I missions the effect of variations in $\mathbf{k}, \gamma$, and assumed payload ratio are all contained in the logarithmic term of equation (25). For type II missions, since $\gamma$ is optimized and $\mathrm{k}$ is assumed negligible, only the effect of payload ratio appears in the mission equation (eq. (26)). The effects on mission distance for a given trip time obtained from these equations are shown in figure 8 , where $R_{o}$ is the distances for $k=$ $\gamma=0$ with type $I$ and for payload ratio per stage of 0.1 for both types. Mission capa-

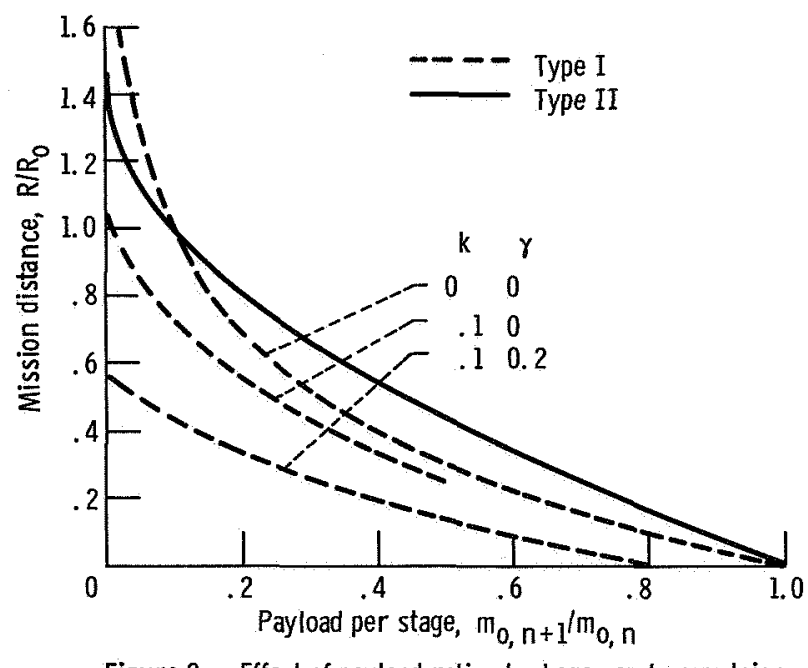

Figure 8. - Effect of payload ratio, tankage, and propulsion system mass on mission distance. Field-free space. 
bility is quite sensitive to values of tankage and propulsion system mass ratio for type I systems. The trip times plotted for $\mathrm{k}=\gamma=0$ on previous figures are therefore optimistic, particularly for relatively heavy propulsion systems such as gaseous-core fission rockets, where minimum values of $\mathrm{mps}_{\mathrm{ps}}$ in the range of $10^{5}$ kilograms or more are estimated for the specific impulse range near and above 5000 seconds (ref. 2).

\section{CONCLUSIONS}

Comparison of missions in gravity-free space with more realistic mission studies shows that the gravity-free approximation provides good estimates of trip time as function of propulsion system parameters, not only for interstellar distances but also for planetary missions. The agreement, however, is limited to these missions that do not require escape from or descent to low orbits about the major planets. The field-free equations are therefore useful for preliminary evaluation of the mission capability of advanced propulsion system concepts.

Comparisons show that, among the most advanced concepts for which performance estimates are available, the pulsed (microbomb) fusion rocket and the radiation-cooled gaseous-core fission rockets provide the fastest trip times to the near planets. Of these two systems, the pulsed fusion system, if its estimated lower mass prevails, would be superior. For round trips to Jupiter and beyond, the controlled-fusion system shows progressively greater trip time advantages. For missions involving the establishment of low orbits about major planets, this advantage exists only for more distant planets. Because of the very large uncertainties in current performance estimates, the only conclusion warranted at present is that these advanced concepts are competitive for future planetary missions. Concepts based on the use of impinging laser beams (remotely generated) are limited to flyby propulsion, and require vast amounts of power for modest payload. They do not, therefore, seem competitive with the advanced onboard propulsion concepts for the range of missions considered.

\section{Lewis Research Center,}

National Aeronautics and Space Administration, Cleveland, Ohio, July 11, 1972, 112-28. 


\section{APPENDIX A}

\section{SYMBOLS}

A area of laser-propelled photon sail

a acceleration

d initial diameter of laser beam

$d_{s} \quad$ diameter of photon sail

F thrust

$\mathrm{g}_{\mathrm{o}}$ gravitational acceleration at Earth's surface, $9.8 \mathrm{~m} / \mathrm{sec}^{2}$

I specific impulse

$I_{e q}$ equivalent specific impulse of impinging-laser system

J mission difficulty parameter for type II systems

$\mathrm{K}$ initial acceleration of photon sail with full reflection

$\mathrm{k} \quad$ ratio of tankage mass to propellant mass

m mass

$\mathrm{N}$ number of stages

$\mathbf{P}_{\mathbf{j}} \quad$ exhaust jet power

$\mathbf{P}_{l} \quad$ laser beam power density

$\mathbf{P}_{\mathrm{o}} \quad$ laser beam power

$\mathrm{p}_{l} \quad$ laser beam pressure

$\mathrm{R}$ distance from origin

$r$ nondimensional distance, $R / R_{1}$

T total trip time

$\mathrm{T}_{\mathrm{p}} \quad$ propulsion time

$t$ time

v velocity

$\Delta \mathrm{v} \quad$ velocity increment

$\alpha \quad$ specific mass, $\mathrm{kg} / \mathrm{W}$

$\alpha^{\prime} \quad$ specific mass, $\mathrm{kg} / \mathrm{kW}$ 
$\gamma \quad$ ratio of propulsion system mass to initial total mass

$\epsilon \quad$ emissivity

$\eta \quad$ reflectivity

$\theta$ diffraction-limited divergence angle

$\lambda \quad$ wavelength

$\rho \quad$ density, $\mathrm{kg} / \mathrm{m}^{3}$

$\rho_{\mathrm{s}} \quad$ surface density, $\mathrm{kg} / \mathrm{m}^{2}$

$\sigma \quad$ Stefan-Boltzmann constant, $5.67 \times 10^{-8}, \mathrm{~W} /\left(\mathrm{m}^{2}\right)(\mathrm{K})^{4}$

$\tau$ nondimensional time, $t / t_{1}$

Subsc ripts:

c circular

j jet

n $n^{\text {th }}$ stage

- initial values

pay payload

pr propellant

ps propulsion system

s structure

$t$ tankage

1 values at $R=R_{1}$ 


\section{APPENDIX B}

\section{PROPULSION BY IMPINGING LASER BEAM}

To estimate the best mission performance of a photon sail system using an impinging laser beam, assume that diffraction limited divergence of the beam can be achieved and no atmospheric effects exist. The resulting beam and sail geometry is illustrated in the following sketch:

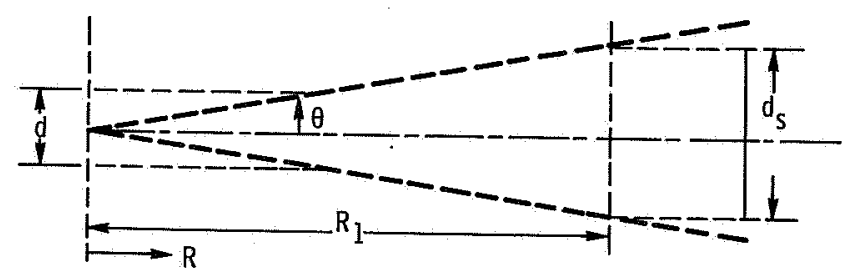

The diffraction-limited divergence angle $\theta$ is given by

$$
\sin \theta \approx \theta=1.22 \frac{\lambda}{d}
$$

Here $\lambda$ is the wavelength and $d$ the diameter of the optical system that collimates the beam.

The distance $R_{1}$ corresponds to a beam diameter equal to the sail diameter $d_{S}$. For $R<R_{1}$, the beam is assumed to be expanded to fill the entire sail, so that constant acceleration is maintained. For $R>R_{1}$, the beam power density on the sail decreases as $\mathrm{R}^{-2}$, and the acceleration also drops. The expression for $R_{1}$ is

$$
\mathrm{R}_{1} \approx \frac{\mathrm{d}_{\mathrm{S}}}{2 \theta}=\frac{\mathrm{d}_{\mathrm{S}} \mathrm{d}}{2.44 \lambda}
$$

The pressure $\mathrm{p}_{l}$ on the sail, in terms of the laser beam power density $\mathrm{P}_{l}$, is

$$
\mathrm{p}_{\imath}=\frac{2 \mathrm{P}_{\imath}}{\mathrm{c}} \mathrm{N} / \mathrm{m}^{2}
$$

where $\mathrm{c}$ is the speed of light, and the factor 2 is for the assumed specular reflection of the beam. The beam power density is, for $R \leq R_{1}$, 


$$
P_{l}=P_{l o}=\frac{P_{0}}{\frac{\pi}{4} d_{s}^{2}}
$$

and, for $R>R_{1}$,

$$
\mathrm{P}_{\ell}=\frac{\mathrm{P}_{l 0}}{\left(\frac{\mathrm{R}}{\mathrm{R}_{1}}\right)^{2}}
$$

where $P_{0}$ is the total initial power in the laser beam.

The vehicle mass can be written as

$$
\begin{aligned}
m_{o} & =m_{p s}+m_{s}+m_{p a y} \\
& =m_{p s}\left(1+m^{\prime}\right)
\end{aligned}
$$

where $\mathrm{m}_{\mathrm{ps}}$ is propulsion system mass (mostly the sail), $\mathrm{m}_{\mathrm{s}}$ is structure mass, and $\mathrm{m}_{\text {pay }}$ is payload mass. The quantity $\mathrm{m}^{\prime}$ is the ratio of the sum of the latter masses to $\mathrm{m}_{\mathrm{ps}}$. If $\mathrm{A}_{\mathrm{s}}$ is the sail area, the acceleration of the vehicle can be written as

$$
\ddot{\mathrm{R}}=\frac{\mathrm{p}_{l} \mathrm{~A}_{\mathrm{s}}}{\mathrm{m}_{\mathrm{ps}}\left(1+\mathrm{m}^{\prime}\right)}=\frac{\mathrm{p}_{l}}{\rho_{\mathrm{s}}\left(1+\mathrm{m}^{\prime}\right)}
$$

where $\rho_{\mathbf{S}}$ is the mass per unit area of the sail. (Note that this acceleration remains finite even if $\mathrm{m}_{\mathrm{ps}}$ goes to zero.) Combining the preceding equations yields

$$
\begin{gathered}
\ddot{R}=K \text { for } R \leq R_{1} \\
\ddot{R}=K\left(\frac{R}{R_{1}}\right)^{-2} \text { for } R>R_{1}
\end{gathered}
$$

where

$$
K=\frac{2 P_{l o}}{\rho_{s} c\left(1+m^{\prime}\right)}
$$

From equation (B8) the conditions at the location where beam diameter equals sail diameter are 


$$
\left.\begin{array}{c}
\mathrm{t}_{1}=\sqrt{\frac{2 \mathrm{R}_{1}}{\mathrm{~K}}} \\
\mathrm{v}_{1}=\mathrm{Kt}_{1}=\sqrt{2 \mathrm{R}_{1} \mathrm{~K}}
\end{array}\right\}
$$

where $R_{1}$ is given by equation (A2). Nondimensionalizing equations (B8) and (B9) with $\mathrm{r}=\mathrm{R} / \mathrm{R}_{1}, \quad \tau=\mathrm{t} / \mathrm{t}_{1}$ yields

$$
\left.\begin{array}{cc}
\ddot{r}=2 & \text { for } r \leq 1 \\
r^{2} \ddot{r}=2 & \text { for } r>1
\end{array}\right\}
$$

with conditions $r_{1}=t_{1}=1 ; \dot{r}_{1}=\ddot{r}_{1}=2$. Figure 9 shows the variation of $r, \dot{r}$, and $\ddot{r}$ with $\tau$. These results show that, because of the rapid reduction in acceleration beyond $\tau=1$, there is little increase in velocity beyond $R=R_{1}$. In fact, first integration of (B12) shows that $\dot{r} \rightarrow 2 \sqrt{2}$ as $r \rightarrow \infty$. Cons equently from equations (B10) and (B11), the velocity increment $\Delta \mathrm{v}$ can be written as

$$
\Delta \mathrm{v}=\sqrt{2} \mathrm{v}_{1}=\sqrt{2}\left(\frac{\mathrm{dd}_{\mathrm{s}}}{1.22 \lambda}\right)^{1 / 2}\left[\frac{2 \mathrm{P}_{\ell \mathrm{o}}}{\rho_{\mathrm{s}} \mathrm{c}\left(1+\mathrm{m}^{\prime}\right)}\right]^{1 / 2}
$$

Thus, the mission capability of the impinging-laser photon sail depends on laser wavelength, size of the optical system and sail, the power density that can be tolerated

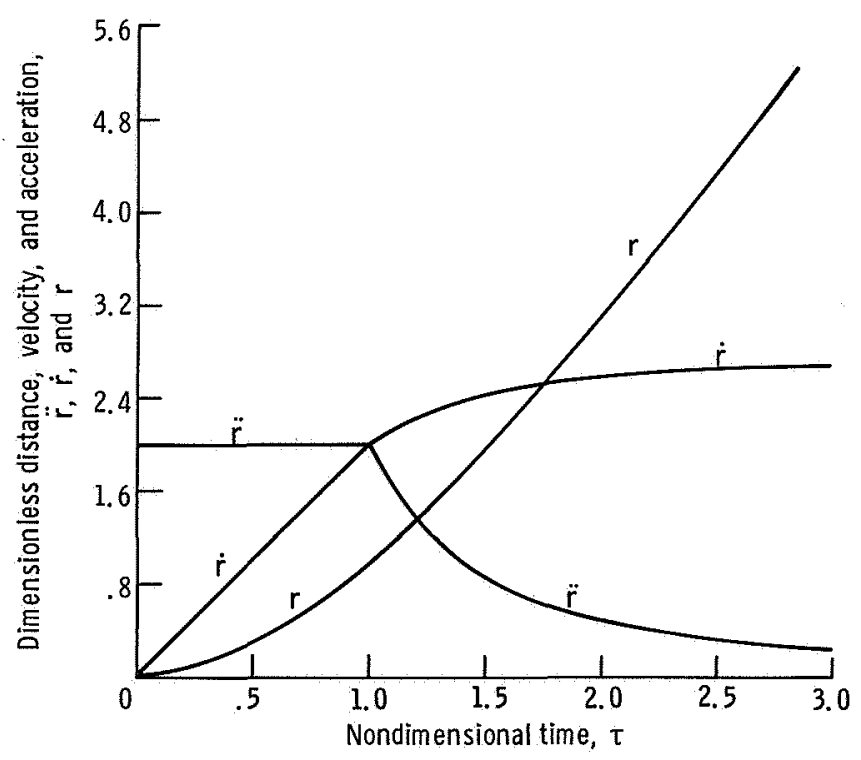

Figure 9. - Nondimensional time history of distance, velocity, and acceleration for propulsion by reflection of laser beam. 
by the sail, and the lowest achievable sail mass per unit area.

For a radiation-cooled sail (both surfaces radiating) the maximum tolerable impinging power density is

$$
\mathrm{P}_{Z_{0}}=\frac{2 \sigma \epsilon \mathrm{T}_{\mathrm{r}}^{4}}{1-\eta}
$$

where $\sigma$ is the Stefan-Boltzmann constant $\left(5.67 \times 10^{-8} \mathrm{~W} /\left(\mathrm{m}^{2}\right)(\mathrm{K})^{4}\right), \mathrm{T}_{\mathrm{r}}$ is the maximum allowable reflector temperature, $\epsilon$ is the total emissivity at the temperature $\mathrm{T}_{\mathrm{r}}$, and $\eta$ is the reflectivity at the laser wavelength $\lambda$. No other cooling method appears feasible because of the need to maintain low reflector mass.

Equations (B13) and (B14) show that a number of reflector properties are involved in maximizing the total $\Delta \mathrm{v}$ attainable. These are, in fact, the same properties that optimize solar sail performance. For that application, an aluminum coating on plastic film was found to be promising, because of its high value of $\epsilon /(1-\eta)$ and low value of $\rho_{\mathrm{S}}$, even though the allowable temperature is quite low. For this material, the following parameters seem achievable (ref. 16$): \epsilon /(1-\eta) \approx 4, \mathrm{~T}_{\mathrm{r}}=400 \mathrm{~K}, \rho_{\mathrm{s}} \approx 10^{-2}$ kilog rams per square meter. With these values and assuming $m^{\prime}=0.1$, the power density and total velocity increment become

$$
\left.\begin{array}{l}
\mathrm{P}_{l 0} \approx 10^{4} \mathrm{~W} / \mathrm{m}^{2} \\
\Delta \mathrm{v} \approx 0.1\left(\frac{\mathrm{dd}_{\mathrm{s}}}{\lambda}\right)^{1 / 2}
\end{array}\right\}
$$

and the initial acceleration, $\mathrm{K}$, is $7 \times 10^{-3}$ meter per second squared, corresponding to a thrust-weight ratio of about $7 \times 10^{-4}$.

To see if we might do better with a higher-temperature but heavier material, consider a thin metallic foil with $\epsilon /(1-\eta) \approx 1, \rho_{S} \approx 10^{-1}$ kilogram per square meter (corresponding to a thickness of order $10^{-5} \mathrm{~m}$ ) and a maximum reflector temperature of $2000 \mathrm{~K}$. For this material

$$
\left.\begin{array}{c}
\mathrm{P}_{l 0} \approx 1.8 \times 10^{6} \mathrm{~W} / \mathrm{m}^{2} \\
\mathrm{~K} \approx 0.08 \mathrm{~m} / \mathrm{sec}^{2} \\
\mathrm{~V} \approx 0.45\left(\frac{\mathrm{dd}_{\mathrm{s}}}{\lambda}\right)^{1 / 2} \mathrm{~m} / \mathrm{sec}
\end{array}\right\}
$$


This material, if achievable, therefore yields a factor of about 5 better $\Delta v$ than the aluminum-coated plastic.

Comparison of this value of $\Delta v$ with equation (10) (with $\mathrm{m}_{\mathrm{pay}} / \mathrm{m}_{\mathrm{o}}=0.1, \mathrm{~N}=1$ ) shows that the laser-propelled sail system is equivalent to a type I system with specific impulse given by

$$
I_{e q}=0.02\left(\frac{d_{s}}{\lambda}\right)^{1 / 2} \text { sec }
$$

For a laser wavelength in the optical range $\left(\lambda \approx 5000 \AA=0.5 \times 10^{-6} \mathrm{~m}\right)$, this becomes

$$
\mathrm{I}_{\mathrm{eq}} \approx 28\left(\mathrm{dd}_{\mathrm{s}}\right)^{1 / 2}
$$

Thus, extremely large beams and sails are needed to produce interesting performance. For example, to produce mission capability (flyby) comparable with a type I system with $I=1000$ seconds requires a product of beam diameter and sail diameter of 1300 square meters. If $d_{s} / d=100$, then $d_{s}=360$ meters and equations (B4) and (B16) show that the required beam power would be $P_{0}=180000$ megawatts. The vehicle mass propelled by this beam would be about 10000 kilograms, of which about 1000 kilograms is payload.

Equation (B13) shows that more attractive performance might be obtainable if $\mathrm{X}$-ray lasers could be developed. For this case, little reflection is to be expected, so that the factor of 2 in equations (B3), (B10), and (B13) is eliminated. The allowable power density would be the same as in equation (B16), since $\epsilon \approx 1, \eta \approx 0$ can be assumed. The sail density per unit area $\rho_{S}$, however, must be estimated on the basis of stopping power for the X-ray wavelength to be used. For a typical example, consider $\lambda=1 \AA\left(=10^{-10} \mathrm{~m}\right)$. The mass absorption coefficient of steel at this wavelength is about 100 square centimeters per gram, so that a surface density of about 0.1 kilogram per square meter is needed to absorb $\mathrm{e}^{-1}$ of the beam power. Thus $\rho_{\mathrm{s}}$ (and resulting foil thickness) is about the same as for the metal foil of the previous example. The minimum $\rho_{\mathbf{s}}$, therefore, appears to be limited by structural and handling problems rather than by absorption, so that the higher mass absorption coefficients that are obtainable at higher $\mathrm{X}$-ray wavelengths would probably not be beneficial. With the same $\rho_{\mathbf{s}}$ and $\mathrm{P}_{20}$, the acceleration is one-half of that of the preceding optical-laser example. Equation (B13) yields

$$
\Delta \mathrm{v} \approx 2.5 \times 10^{4}\left(\mathrm{dd}_{\mathrm{s}}\right)^{1 / 2} \mathrm{~m} / \mathrm{sec}
$$

and the equivalent specific impulse becomes 


$$
\mathrm{I}_{\mathrm{eq}} \approx 1400\left(\mathrm{dd}_{\mathrm{S}}\right)^{1 / 2}
$$

which is a factor of 50 higher than for the optical-laser case. Thus, performance equivalent to that of the best estimated type I system (but only for the flyby mission) would require a product of beam diameter and sail diameter of only 25 square meters. Again, if $d_{s} / d=100$, then $d_{s}=50$ meters, and the beam power required is 3500 megawatts. With this diameter and power, however, the mass of the vehicle propelled is only about 200 kilograms, with a payload about 20 .

From these calculations and because it is limited to flyby missions, we may conclude that propulsion by impinging laser beams is not competitive with advanced onboard propulsion concepts for missions in the solar system.

One other calculation, however, is of interest for this X-ray laser propulsion concept, as suggested in reference 7. Equation (B20) shows that the equivalent specific impulse is limited only by the feasible beam and sail diameters. Consequently, if highly collimated, X-ray laser beams are found to be possible, a laser-propelled vehicle could be developed to reach interstellar distances faster than with any of the other propulsion concepts considered. Figure 2(a) shows that $\alpha$-Centauri (4 light years) could be reached in 10 years with an equivalent specific impulse of $10^{6}$ seconds. For $d_{S} / d=1.0$ (higher ratios yield too high a vehicle mass), the sail diameter (and beam diameter) to achieve this value would be about 1000 meters, and the beam power would be about $10^{6}$ megawatts, which exceeds the current electric power consumption of the world. The vehicle mass propelled would be about $10^{5}$ kilograms. Thus, some future generation of mankind, with a somewhat different ordering of priorities than ours and much more available power, could conceivably explore other stars and other solar systems with highly sophisticated unmanned spacecraft capable of relaying information in elapsed times of the order of decades. 


\section{REFERENCES}

1. Moeckel, Wolfgang E. : Propulsion Systems for Manned Exploration of the Solar System. Astronautics and Aeronautics, vol. 7, no. 8, Aug. 1969, pp. 66-77. (See also NASA TM X-1864, 1969.)

2. Ragsdale, Robert G.: Status of Open-Cycle Gas-Core Reactor Project Through 1970. NASA TM X-2259, 1971.

3. Reinmann, John J.: Fusion Rocket Concepts. NASA TM X-67826, 1971.

4. Reinmann, John J.; and Rayle, Warren D.: Deuterium-Helium-3 Fusion Power Balance Calculations. NASA TM X-2280, 1971.

5. Boyer, Keith; and Balcomb, J. D.: Systems Studies of Fusion Powered Pulsed Propulsion Systems. Paper 71-636, AIAA, June 1971.

6. Rom, Frank E.; and Putre, Henry A.: Laser Propulsion. NASA TM X-2510, 1972.

7. Marx, G. : Interstellar Vehicle Propelled by Terrestrial Laser Beam. Nature, vol. 211, no. 5044, July 2, 1966, pp. 22-23.

8. Redding, J. L. : Interstellar Vehicle Propelled by Terrestrial Laser Beam. Nature, vol. 213, no. 5076, Feb. 11, 1967, pp. 588-589.

9. Fishbach, Laurence H.; and Willis, Edward A., Jr.: Performance Potential of Gas-Core and Fusion Rockets: A Mission Applications Survey. NASA TM $\mathrm{X}-67940,1971$.

10. Dugan, James F., Jr.: Analysis of Trajectory Parameters for Probe and RoundTrip Missions to Mars. NASA TN D-281, 1960.

11. Dallas, S. S.: High-Energy Trajectories from Earth to Mars and Return. Rep. JPL-TR-32-803, Jet Propulsion Lab., California Inst. Tech. (NASA CR-69221), Dec. 15, 1965.

12. Sauer, Carl G., Jr.; and Melbourne, William G.: Optimum Earth-to-Mars Roundtrip Trajectories Utilizing a Low-Thrust Power-Limited Propulsion System. Advances in the Astronautical Sciences. Vol. 13. Eric Burgess, ed., Western Periodicals Co., 1963, pp. 547-570.

13. Fishbach, Laurence H.; Giventer, Lawrence L. ; and Willis, Edward A., Jr.: Approximate Trajectory Data for Missions to the Major Planets. NASA TN D-6141, 1971.

14. Moeckel, W. E.: Trajectories with Constant Tangential Thrust in Central Gravitational Fields. NASA TR R-53, 1960. 
15. Mascy, Alfred C.; Dugan, Duane W.; and Pitts, Samuel W.: Applications of Combined Electric, High-Thrust Propulsion Systems. J. Spacecraft Rockets, vol. 5, no. 7, July 1968, pp. 785-791.

16. Babjak, S. J.; et al.: Planetary Vehicle Thermal Insulation Systems. Rep. DIN68SD4266, General Electric Co. (NASA CR-95253), June 3, 1968. 


\begin{tabular}{|c|c|c|c|c|}
\hline $\begin{array}{l}\text { 1. Report No. } \\
\text { NASA TN D-6968 }\end{array}$ & \multicolumn{2}{|c|}{ 2. Government Accession No. } & \multicolumn{2}{|c|}{ 3. Recipient's Catalog No. } \\
\hline \multirow{2}{*}{\multicolumn{3}{|c|}{$\begin{array}{l}\text { 4. Title and Subtitle } \\
\text { COMPARISON OF ADVANCED PROPULSION CONCEPTS FOR } \\
\text { DEEP SPACE EXPLORATION }\end{array}$}} & \multicolumn{2}{|c|}{$\begin{array}{l}\text { 5. Report Date } \\
\text { September } 1972\end{array}$} \\
\hline & & & \multicolumn{2}{|c|}{ 6. Performing Organization Code } \\
\hline $\begin{array}{l}\text { 7. Author(s) } \\
\text { W. E. Moeckel }\end{array}$ & & & \multicolumn{2}{|c|}{$\begin{array}{l}\text { 8. Performing Organization Report No. } \\
\text { E- } 6798\end{array}$} \\
\hline \multirow{3}{*}{\multicolumn{3}{|c|}{$\begin{array}{l}\text { 9. Performing Organization Name and Address } \\
\text { Lewis Research Center } \\
\text { National Aeronautics and Space Administration } \\
\text { Cleveland, Ohio } 44135\end{array}$}} & \multicolumn{2}{|l|}{$\begin{array}{l}\text { 10. Work Unit No. } \\
112-28\end{array}$} \\
\hline & & & \multicolumn{2}{|c|}{ 11. Contract or Grant No. } \\
\hline & & & \multirow{2}{*}{\multicolumn{2}{|c|}{$\begin{array}{l}\text { 13. Type of Report and Period Covered } \\
\text { Technical Note }\end{array}$}} \\
\hline \multirow{2}{*}{\multicolumn{3}{|c|}{$\begin{array}{l}\text { 12. Sponsoring Agency Name and Address } \\
\text { National Aeronautics and Space Administration } \\
\text { Washington, D.C. } 20546\end{array}$}} & & \\
\hline & & & \multicolumn{2}{|c|}{ 14. Sponsoring Agency Code } \\
\hline \multicolumn{5}{|l|}{ 15. Supplementary Notes } \\
\hline \multicolumn{5}{|c|}{$\begin{array}{l}\text { 16. Abstract } \\
\text { Equations and charts are presented that permit rapid estimation of propulsion-system perfor- } \\
\text { mance requirements for some typical deep-space missions. A number of advanced propulsion } \\
\text { concepts for which performance estimates are available are compared with respect to their } \\
\text { capability for flyby, rendezvous, and roundtrip planetary missions. Based on these estimates, } \\
\text { the gas-core nuclear fission rocket and the pulsed fusion rocket yield the fastest trip times to } \\
\text { the near planets. For round trips to Jupiter and beyond, the controlled fusion rocket shows } \\
\text { progressively superior capabilities. Several propulsion concepts based on use of impinging } \\
\text { laser beams are found to be noncompetitive with the other advanced concepts for deep space } \\
\text { missions. Requirements for attainment of interstellar distances within a human lifetime are } \\
\text { found to be some orders of magnitude beyond the capabilities of any propulsion concepts for } \\
\text { which performance estimates are now possible. }\end{array}$} \\
\hline \multicolumn{2}{|c|}{$\begin{array}{l}\text { 17. Key Words (Suggested by Author(s)) } \\
\text { Space propulsion; Space missions; Space } \\
\text { vehicles; Nuclear propulsion; Laser propul- } \\
\text { sion; Fusion propulsion }\end{array}$} & \multicolumn{3}{|c|}{$\begin{array}{l}\text { 18. Distribution Statement } \\
\text { Unclassified - unlimited }\end{array}$} \\
\hline $\begin{array}{r}\text { 19. Security Classif. (of this report) } \\
\text { Unclassified }\end{array}$ & $\begin{array}{r}\text { 20. Security Classi } \\
\mathrm{U}\end{array}$ & $\begin{array}{l}\text { this pagel } \\
\text { lassified }\end{array}$ & $\begin{array}{c}\text { 21. No. of Pages } \\
36\end{array}$ & $\begin{array}{r}\text { 22. } \text { Price }^{*} \\
\$ 3.00\end{array}$ \\
\hline
\end{tabular}

* For sale by the National Technical Information Service, Springfield, Virginia 22151 
"The aeronautical and space activities of the United States shall be conducted so as to contribute ... to the expansion of buman knowledge of phenomena in the atmosphere and space. The Administration shall provide for the widest practicable and appropriate dissemination of information concerning its activities and the results thereof."

\section{NASA SCIENTIFIC AND TECHNICAL PUBLICATIONS}

TECHNICAL REPORTS: Scientific and technical information considered important, complete, and a lasting contribution to existing knowledge.

TECHNICAL NOTES: Information less broad in scope but nevertheless of importance as a contribution to existing knowledge.

TECHNICAL MEMORANDUMS:

Information receiving limited distribution because of preliminary data, security classification, or other reasons.

CONTRACTOR REPORTS: Scientific and technical information generated under a NASA contract or grant and considered an important contribution to existing knowledge.
TECHNICAL TRANSLATIONS: Information published in a foreign language considered to merit NASA distribution in English.

SPECIAL PUBLICATIONS: Information derived from or of value to NASA activities. Publications include conference proceedings, monographs, data compilations, handbooks, sourcebooks, and special bibliographies.

TECHNOLOGY UTILIZATION PUBLICATIONS: Information on technology used by NASA that may be of particular interest in commercial and other non-aerospace applications. Publications include Tech Briefs, Technology Utilization Reports and

Technology Surveys.

Details on the availability of these publications may be obtained from:

SCIENTIFIC AND TECHNICAL INFORMATION OFFICE

NATIONAL AERONAUTICS AND SPACE ADMINISTRATION

Washington, D.C. 20546 